Portland State University

PDXScholar

$10-1-2020$

\title{
Implicit Learning of Children With and Without Developmental Language Disorder Across Auditory and Visual Categories
}

Wanchi Yu

Portland State University

Follow this and additional works at: https://pdxscholar.library.pdx.edu/open_access_etds

Part of the Communication Sciences and Disorders Commons

Let us know how access to this document benefits you.

Recommended Citation

Yu, Wanchi, "Implicit Learning of Children With and Without Developmental Language Disorder Across Auditory and Visual Categories" (2020). Dissertations and Theses. Paper 5588.

https://doi.org/10.15760/etd.7460

This Thesis is brought to you for free and open access. It has been accepted for inclusion in Dissertations and Theses by an authorized administrator of PDXScholar. Please contact us if we can make this document more accessible: pdxscholar@pdx.edu. 
Implicit Learning of Children with and without Developmental Language Disorder across Auditory and Visual Categories

by

Wanchi Yu

A thesis submitted in partial fulfillment of the requirements for the degree of

Master of Science

in

Speech and Hearing Sciences

Thesis Committee:

Carolyn Quam, Chair

Molly Franz

Sarah Key-DeLyria

Portland State University

2020 
(C2020 Wanchi Yu 


\begin{abstract}
The current study examined implicit sound- and visual-meaning-mappings of children with and without Developmental Language Disorder (DLD).

One child with DLD and 29 children with typical language development (TLD) were included in the study, based on results from a hearing screening and standardized assessments of cognitive and expressive language skills. Participants completed two computer-based experiments, which were designed to investigate: 1) sound discrimination (pitch and duration), implicit mapping of sound stimuli to objects; 2) visual discrimination, implicit mapping of visual stimuli to objects.

The current study showed that children with TLD who implicitly learned pitch categories showed better mapping of sound stimuli to objects than children with TLD who implicitly learned duration categories. The one child with DLD who learned pitch categories showed implicit learning in the mapping task. The child also showed implicit learning of visual stimuli in the visual experiment. An association between sounddiscrimination scores and sound mapping performance in multivariate analyses of covariance (MANCOVAs) was not found in the TLD group. An interaction between visual discrimination and phase in the test block was found. Correlation tests revealed a negligibly positive association between visual discrimination and visual learning of the second phase in the test block in the TLD group, suggesting that links were starting to appear as children learned the categories.
\end{abstract}

Findings are discussed in the context of recruitment challenges, and potential experimental design adjustments are suggested for future work. 


\section{DEDICATION}

To my precious friends - Wesley Chan and Grace Liao, KaoXu Chang, Juston Li, Larry, Nola, and Melissa Spaulding, Beverly Wanvig, and

Robert and Xeng Yen Yang, whose loving words and taking care of me have always sustained me in the past three years of my life. 


\section{ACKNOWLEDGEMENTS}

I am grateful to Dr. Carolyn Quam and Molly Franz for giving me the opportunity to learn how to collaborate with lab members to conduct research in the Child Language Learning Center (CLLC) lab at Portland State University and encouraging me to start working on this project. I thank them for their mentorship, supervision, patience, and willingness to listen and share.

I also want to thank Chia-Cheng Lee for introducing me to the CLLC lab, without whom I would not have started this journey.

I am thankful to Sarah Elkinton for showing her understanding of facing road- blocks through her own experience of writing her thesis, discussing statistics with me, and offering to read my drafts through her accountability.

I also want to acknowledge the time Dr. Todd Bodner, Dr. Gerasimos Fergadiotis, Dr. Sarah Key-DeLyria, and Dr. Megann McGill have taken to discuss doing research with me.

Thanks to student researchers and research Speech-Language Pathologists who made this study possible: Rachel Atkinson, Megan Berry, Thomas Brown, Holly Cardinal, Lauren Casey, Kirsten Davis, Sarah Elkinton, Josie Johnson, Aminah Abdirahman, Celeste Gallegos, Roxana Magee, Eliza Minculescu, Karin Nystrom, Brandie Romanko, Carole Salmo, Allison

Schierholtz, Claire Small, and Abigail E Tolomei. For those of you I have had the chance to work with, I am grateful to have the opportunity to learn from you.

As always, thanks to children, their families, and staff members at the children's preschools who dedicated their time and energy to participate in the current study.

If I were to write down all the people who have encouraged and 
influenced me on this journey, two pages would not be enough. However, I would at least include: Cai Fei, Mika Gil, Dr. Christina GildersleeveNeumann, Professor Susan Ginley, Sam and Amanda Huang, Dom and Christine Kan, Dr. Maria Kapantzoglou, Professor Janet Lambert, Dr. Jennifer Larsen, Joey Lim, Caleb Lu and Anya Kwasnik, Ma Mingxin, Daniela Marquina Cuevas, Daniela Myovich, Mi (Eve) Ngo, Niyongabo Jean- Prime, Professor Teresa Roberts, Jennifer Walsh, Lauren Weerts, Jennifer Wright, Diana Yuen, Anna Zhen and, as always, my family, to whom I owe a deeper debt of gratitude. 


\section{TABLE OF CONTENTS}

ABSTRACT.

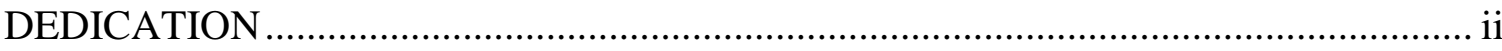

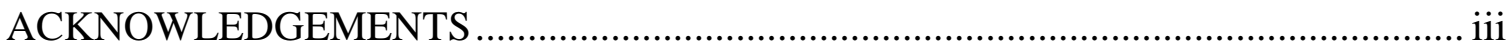

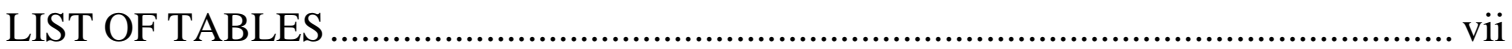

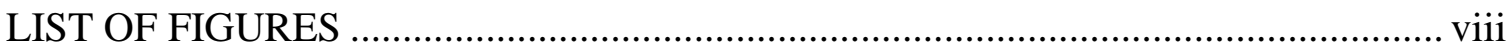

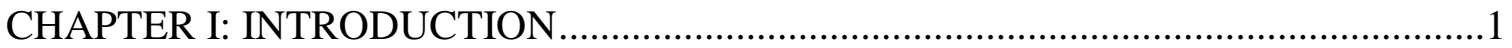

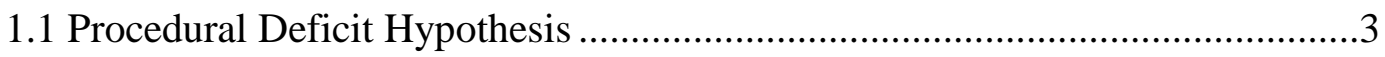

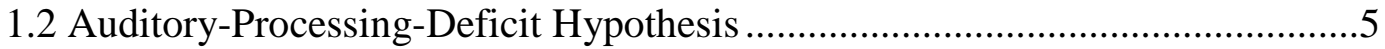

1.3 Prior Studies Related to the Current Study ................................................

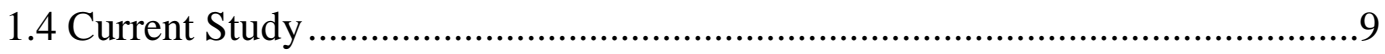

CHAPTER II: EXPERIMENT ONE: IMPLICIT SOUND LEARNING .......................12

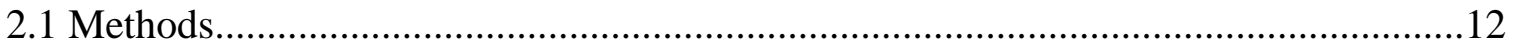

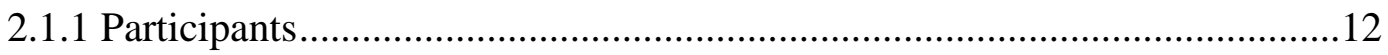

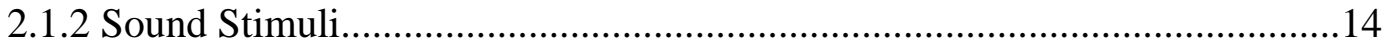

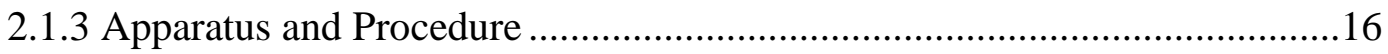

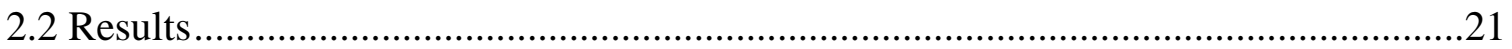

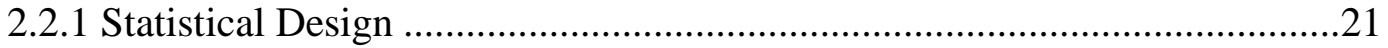

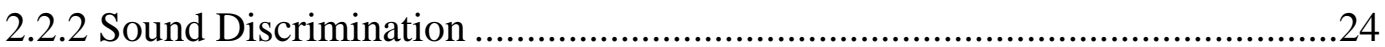




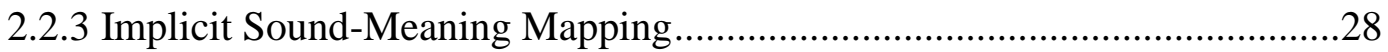

2.2.4 Linking Sound Discrimination and Implicit Sound-Meaning Mapping ........31

2.3 Discussion .34

CHAPTER III: EXPERIMENT TWO: IMPLICIT VISUAL LEARNING .38

3.1 Methods. .38

3.1.1 Visual Stimuli .38

3.1.2 Apparatus and Procedure

3.2 Results 42

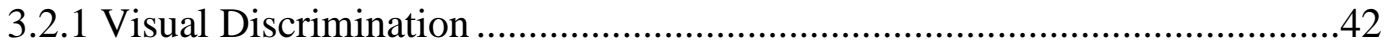

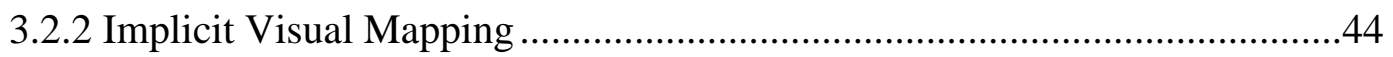

3.2.3 Linking Visual Discrimination and Implicit Visual Mapping ..................... 48

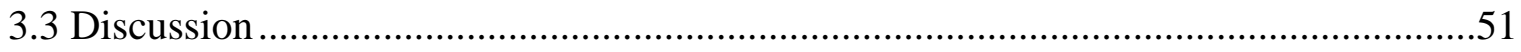

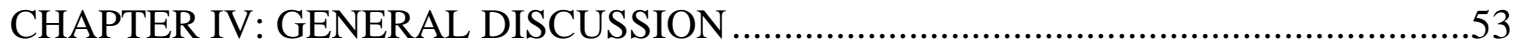

4.1 Compare and Contrast: Experiment One and the Previous Explicit Study ..................53

4.2 Compare and Contrast: Experiment One and Experiment Two.................................. 54

4.3 Overall Findings and the Primary Hypothesis ...........................................................55

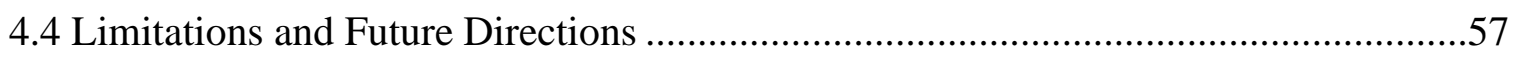

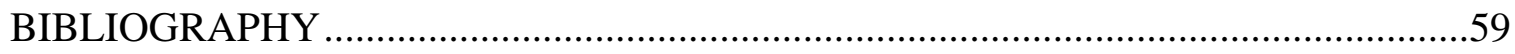




\section{LIST OF TABLES}

Table 1: Comparison of Task Designs in Four Experiments: Adapted from Quam et al. (in prep). 11 Table 2: Demographic information and standardized test scores for children with TLD and one child with DLD. 13

Table 3: Auditory d-prime scores across five distances for children with TLD (mean, standard deviation, and range) and one child with DLD (mean).

Table 4: Accuracy of the auditory mapping of children with TLD and one child with DLD .

Table 5: Reaction time (seconds) of the auditory-mapping of children with TLD and one child with DLD

Table 6: Visual d-prime scores across five distances for children with TLD (mean, standard deviation, and range) and one child with DLD (mean).

Table 7: Accuracy of the visual mapping of children with TLD and one child with DLD

Table 8: Reaction time (seconds) of the visual-mapping of children with TLD and one

child with DLD 


\section{LIST OF FIGURES}

Figure 1: Duration (in seconds) and pitch (in semitones) for the 12 auditory stimuli used in Experiment.

Figure 2: Either Leonard's favorite drink (left) or his favorite food (right) appears on the

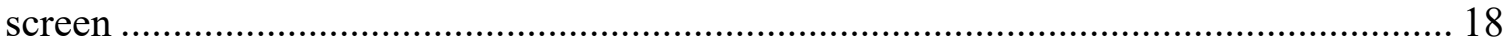

Figure 3: Association (with 95\% confidence intervals) between Sound Discrimination

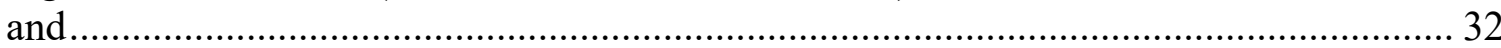

Figure 4: Association (with 95\% confidence intervals) be- tween Sound Discrimination and Mapping in Phase Two of the Test Block....................................................... 33

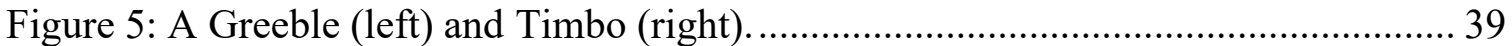

Figure 6: Greebles on a continuum: Adapted from Quam et al. (2019). ......................... 40

Figure 7: Timbos on a continuum: Adapted from Quam et al. (2019). ............................ 41

Figure 8: Either the drink (left) or the food (right) appears on the screen next to ........... 42

Figure 9: Association (with 95\% confidence intervals) be- tween visual discrimination

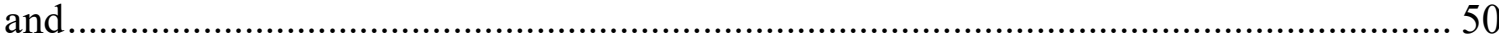

Figure 10: Association (with 95\% confidence intervals) between visual discrimination

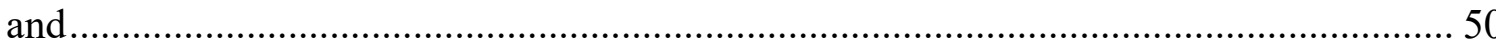




\section{CHAPTER I: Introduction}

The purpose of the present study was to investigate implicit sound- and visualmeaning-mappings of children with and without Developmental Language Disorder (DLD). DLD is a neurodevelopmental language disorder with unknown conditions, not attributable to hearing, cognitive, and neurological differences or disabilities (Bishop et al., 2017). Besides the term DLD, researchers have been using other terms investigating language difficulties of children, such as Specific Language Impairment (SLI) and Primary Language Impairment (PLI). However, each of these terms, along with the term DLD, has its own limitations. For example, the term SLI has been challenged due to the evidence suggesting that children being considered as having SLI not only demonstrate impairments specific to language development and learning but also show impairments in non-linguistic areas (Ullman and Pierpont, 2005). In addition, some researchers find Primary Language Impairment (PLI) can be con- fusing because of the challenge of determining whether a condition is secondary to another condition and because of the widely used term Pragmatic Language Impairment (PLI) in the area of social communication. Besides issues with terms SLI and PLI, examples of objections to the term DLD include 1) "disorder" may indicate medical-based connotation; 2) "developmental" may be associated with language de- lay and may not be appropriate to apply for adolescents or adults who experience language difficulties (Bishop et al., 2017). Although none of the aforementioned labels seem to be perfect, the main goal of having a general consensus on one term is to move research forward and allow individuals with language challenges to have more access to services. The term DLD has been currently voted by 
individuals in areas including research, education, and medical settings from several regions and countries where English is dominantly spoken to describe language difficulties having no association with biomedical conditions (Bishop et al., 2017). For the purpose of the current study, the inclusion criteria for the DLD group in the current study focuses on learning difficulties specific to language.

Language learning difficulties associated with DLD exist across different language domains. Showing difficulty with acquiring grammar (the morphosyntactical aspect of language) and showing weakness in phonological short-term memory for those who do not speak tonal languages (measured by non-word repetition tasks $)^{1}$ are considered as two major characteristics of DLD among English-speaking children (Leonard, 2014a; Leonard, 2014b). Research has also shown that not all of the specific grammatical errors made by children with DLD are cross-linguistic or universally present in different languages (Leonard and Kueser, 2019). In addition to the morphosyntactic aspect of the language, there is evidence that auditory deficits are found among individuals with DLD, such as difficulty with rapid temporal processing (see Leonard, 2014a, for a review). Furthermore, evidence has shown that children with DLD may also have word learning difficulties (e.g., Jackson et al., 2016; Gray, 2006; Alt et al., 2004; Sheng and McGregor, 2010; Gray, 2005).

The current knowledge of DLD does not allow researchers to have a consensus on the etiologies of DLD yet. Some argue that the etiologies of DLD can be multifactorial, and some have also argued that children with DLD may represent as a heterogenous group. In other words, children with DLD may not all have the

\footnotetext{
${ }^{1}$ Non-word repetition tasks have been found not necessarily to be diagnostic for DLD among children who speak tonal languages, which can be explained by the nature of the languages (Stokes et al., 2006). For example, each syllable in Cantonese has a salient tone, and therefore, there is no stress reduction in multisyllablic combinations.
} 
same phenotype pattern. For example, some show more receptive deficits, some more ex- pressive deficits, and some phonological deficits (Kapantzoglou et al., 2015; see van der Lely, 2003, for a review). Thus, different hypotheses have been proposed to con- tribute to the understanding of the potential causes of DLD. The current study was motivated by two kinds of theoretical framework, and its investigation of DLD focused on two hypotheses.

\subsection{Procedural Deficit Hypothesis}

The first hypothesis the current study investigated was the Procedural Deficit Hypothesis (PDH; Ullman and Pierpont, 2005) positing that DLD can be explained by abnormal brain structures underlying procedural memory system, especially the basal ganglia (BG) and its related circuitry. The procedural memory system is considered to be involved in learning new knowledge/skills and "remembering" learned knowledge/skills without consciousness, and it subserves the "implicit memory" system, which has been found to be related to frontal/basal-ganglia structures (Shanks, 1996; see Ullman, 2001; Ullman, 2004, for a review). According to the PDH, procedural memory circuits are associated with both procedural memory functions (e.g., implicit sequence learning, learning of grammatical regularities and phonotactics) and non- procedural functions such as working memory and inhibition in executive function (Henry et al., 2012; Ullman and Pierpont, 2005).

Given that the PDH is based on neuroanatomy, it is currently called the Procedural circuit Deficit Hypothesis (Ullman et al., 2020). In addition, while

originally motivated by explaining the grammatical deficits in DLD (Ullman and Pierpont, 2005), the PDH has been extended from explaining DLD to 
contributing to the understanding of various disorders such as attentiondeficit/hyperactivity disorder, autism spectrum disorder, and dyslexia (Ullman, 2004).

In contrast to the potential impaired procedural memory system in DLD, ac- cording to the PDH, the declarative memory system in DLD is mostly intact and can compensate for procedural deficits. The declarative memory is viewed as learning and memory depending on the medial temporal lobe (MTL) and its associated circuitry (Ullman, 2001; Ullman, 2004).

The procedural/declarative memory systems have been found to be associated with implicit and explicit learning. While both procedural memory and declarative memory, along with several other brain systems, can support implicit learning, explicit learning seems can only occur in the declarative memory system (Ullman, 2016). In addition, while it has been suggested that there may not be a task that purely involves implicit learning or purely involves explicit learning (Cleeremans, 2006), a potential seesaw effect has been observed where weakened BG function may strengthen MTL function, and vice versa (Ullman, 2004).

Evidence has shown that in rule-based category learning, encouraging individuals to focus on underlying dimensions/categories can increase explicit consciousness of the dimensions/categories (see Ashby and Maddox, 2005, for a review) and the absence of providing explicit information or encouragement of paying attention to the underlying categories seems to facilitate implicit learning.

It is important to note that dysfunction of procedural memory is not equal to the inability to learn. Rather, learning may still occur in the procedural memory system, and as mentioned previously, spared declarative memory can 
compensate for learning that requires an individual's procedural memory skills (Ullman and Pierpont, 2005). For example, grammar learning difficulties found in DLD tend to be related to learning of grammatical features that depend on procedural memory and there has been evidence that children with DLD may use declarative memory as compensation to learn grammar (Lum et al., 2012).

Research testing PDH has been conducted among individuals with DLD in different domains since its proposal (e.g., Saletta et al., 2018; Poll et al., 2015; Kemény and Lukács, 2010; Hedenius et al., 2011) and a few of them failed to find evidence that seemed to support the PDH (e.g., Gabriel et al., 2015; Gabriel et al., 2012; Gabriel et al., 2011). According to Ullman et al. (2020), a lack of power or compensation of declarative memory which could potentially facilitate learning even with the presence of procedural learning deficits may be explained why some studies have not confirmed the existence of procedural learning deficits in DLD.

Based on the literature review on PDH, we predict that children with DLD in the current study would show difficulty learning both sound- and visualmeaning mappings implicitly.

\subsection{Auditory-Processing-Deficit Hypothesis}

The second hypothesis the current investigated was the auditory-processing (or speech-processing)-deficit hypothesis (Merzenich et al., 1996; Tallal et al., 1996; Wright et al., 1997) that children with DLD have difficulty with auditory perception. Although, as mentioned above, there has been evidence that children

with DLD have difficulty with temporal processing or rapid auditory processing in non-linguistic areas in general, there has also been evidence that difficulties 
with rapid temporal processing may not exist among children with DLD or at least only has been shown in a subgroup of children with DLD (see Mcarthur and Bishop, 2001, for a review). In addition, examining speech perception processing instead of rapid temporal processing may better help researchers directly investigate the relationship between auditory perception and language impairment among individuals with DLD.

Studies have shown evidence of auditory-processing impairment among individuals with DLD. Cumming et al. (2015); Richards and Goswami (2015); Corriveau et al. (2007) all showed that children with DLD had difficulty with auditory processing, which was related to their lower sensitivity of amplitude rise time and sound duration that are important for processing prosody (e.g., stress), compared to their typically developing peers. Datta et al. (2010) also showed that children with DLD had more difficulty perceiving short-vowel sounds than longer-vowel sounds, compared to their peers with TLD. In addition, it has been shown that children with DLD have deficits in auditory discrimination (see Kujala and Leminen, 2017, for a review).

Some have also argued that the less successful performance of children with DLD on speech perception tasks may not be due to auditory-processing deficits, rather it could be due to cognitive deficits (e.g., memory load; Schwartz et al., 2013; Coady et al., 2007; Coady et al., 2005). However, many participants in prior studies were grade-school children who might be at the later stage of phonological development. Therefore, it is important to test how younger children (e.g., preschoolers) with DLD perform on speech perception tasks compared to their peers with TLD while they are all at the earlier stage of developing phonological skills (Datta et al., 2010).

Apart from the auditory processing hypothesis, the hypothesis of delayed 
auditory maturation or immature auditory processing in DLD (Bishop and Mcarthur, 2004) has been proposed, which extended the auditory-processingdeficit hypothesis by suggesting that children with DLD may have delayed development of speech perception (i.e., auditory perception in DLD can be improved with age). The hypothesis of delayed auditory maturation or immature auditory processing in DLD has been supported by studies such as Oram Cardy et al. (2008) showing delayed auditory perceptual processing in the right hemisphere of individuals with DLD (which could serve as an indicator of oral language skills) and Kwok et al. (2018) revealing delayed maturation of auditory cortical response among 7-10-year-olds with moderatesevere DLD.

The auditory-processing-deficit hypothesis and the related delayed auditory maturation hypothesis would predict that preschoolers with DLD in the current study will show difficulty discriminating sound stimuli and learning sound-meaning mappings implicitly in Experiment One, compared to peers with TLD.

\subsection{Prior Studies related to the Current Study}

The current study was built on two previous studies that investigated implicit and explicit learning of preschoolers with and without DLD in auditory conditions.

Quam et al. (2020) examined the relationship between speech-processing skills and sound-meaning mapping skills among preschoolers by testing the PDH (Ullman and Pierpont, 2005) and the auditory-processing-deficit hypothesis (Merzenich et al., 1996; Tallal et al., 1996; Wright et al., 1997). The study design tried to increase the possibility of showing children's 
sensitivity to links between auditory processing and sound-meaning mapping in three ways: 1) Testing younger children (i.e., preschoolers); 2) Using sound dimensions that are not contrastively used in English (i.e., pitch and duration) to reduce the effect of prior knowledge of English that might have been shown in prior research; 3) Using the same sounds in the discrimination tasks for the mapping tasks, which was different from prior studies that investigated links across different unrelated tasks.

The examination of the relationship between sound discrimination and explicit sound-meaning mapping by preschool-aged children with and without DLD in Quam et al. (2020) revealed: 1) children with TLD showed stronger overall sound discrimination sensitivity than children with DLD;2) children with DLD showed more difficulty mapping sound categories (pitch or duration) to meanings than children with TLD;

3) both groups of children showed more sensitivity to the pitch categories than the duration categories; 4) there was a correlation between sound discrimination and mapping.

Besides finishing the explicit sound-meaning mapping tasks, the same participants in Quam et al. (2020) also completed implicit sound-meaning mapping tasks involving sound categories (pitch or duration), which was designed to test the PDH (Ullman and Pierpont, 2005) by comparing participants' performance across explicit and implicit learning. Children were told to give a monster named Leonard his food or drink. The food and drink were associated with sounds on a continuum. However, an experimental design issue was found after the study: In about $65 \%$ of the trials on the soundmeaning-mapping tasks, the target alternated from the previous target side rather than staying on the same side. Accuracy scores of the sound-meaning- 
mapping tasks confirmed that both children with and without DLD picked up the alternating pattern by guessing that the target picture (Leonard's food or drink) will switch sides from one trial to the next without relying on listening to the sound stimuli. This suggested that both groups of children implicitly learned the target-side alternation, but it prohibited determining whether they learned the intended sound-meaning pairings or not.

The findings of children's explicit learning in Quam et al. (2020) revealing that children with DLD showed more difficulty mapping sound categories to meanings than their peers with TLD and the experimental design issues in the previous implicit learning tasks motivated the design of the current study, aiming to continue testing the PDH (Ullman and Pierpont, 2005) and the auditory-processing-deficit hypothesis (Merzenich et al., 1996; Tallal et al., 1996; Wright et al., 1997).

\section{4 Current Study}

As mentioned above, the current study continued planning to test the PDH (Ullman and Pierpont, 2005) and the auditory-processing-deficit hypothesis (Merzenich et al., 1996; Tallal et al., 1996; Wright et al., 1997) by adopting and making adjust- ments of the experimental design in the previous explicit study (Quam et al., 2020) and the previous implicit study (Quam et al., 2017a; Quam et al., in preparation). The operationalization of examining children's implicit learning remained the same as in the previous implicit study (see Table 1 for comparison among the current study and the previous two studies): In the current study, children were not given explicit feedback during their learning of sound and visual stimuli, which could reduce their reliance on implicit learning. The operationalization of investigating children's auditory 
processing was also similar to that was used in Quam et al. (2020): In the current study, children's auditory processing skills were examined when they participated in sound discrimination tasks that required them to tell sounds apart. In addition, children's auditory processing skills were predicted to be associated with their sound- mapping because children needed to have the capacity to tell sounds apart to map the sounds to the meaning, and this association was found in the prior explicit study. Moreover, in order to address children's difficulty with learning duration categories for both TLD and DLD groups in Quam et al. (2020), the current study adjusted the sound stimuli in two ways to hope to boost children's learning of the duration categories (Please see Chapter 2 for more details).

Furthermore, the current study consists of two experiments: 1) Experiment One that examined children's implicit sound learning; 2) Experiment Two that examined children's implicit visual learning. The added implicit visual learning tasks in Experiment Two was to contrast with children's performance on sound learning tasks in Experiment One. Together with children's performance on explicit sound and visual learning experiments (to be reported elsewhere), as well as implicit sound learning tasks in Experiment One, the implicit visual learning task in Experiment Two will help further test the auditory-processing deficit.

With the experimental design of the current study, we predict that based on the PDH (Ullman and Pierpont, 2005), children with TLD will not show difficulty in either of the two experiments and children with DLD will show difficulty with learning both sound and visual categories implicitly, and that based on the auditory- processing-deficit hypothesis (Merzenich et al., 1996; Tallal et al., 1996; Wright et al., 1997), children with DLD will show more difficulty 
with implicit learning of sound categories than visual categories.

\begin{tabular}{|c|c|c|c|c|}
\hline Study & $\begin{array}{l}\text { Quam et al. } \\
(2020)\end{array}$ & $\begin{array}{l}\text { Quam et } \\
\text { al. } \\
\text { (in prep) }\end{array}$ & $\begin{array}{l}\text { Experimen } \\
\mathrm{t} \\
\text { One of the } \\
\text { current } \\
\text { study }\end{array}$ & $\begin{array}{l}\text { Experimen } \\
t \\
\text { Two of } \\
\text { the current } \\
\text { study }\end{array}$ \\
\hline Implicit/Explicit & Explicit & Implicit & Implicit & Implicit \\
\hline Stimuli & $\begin{array}{l}\text { sound } \\
\text { categories }\end{array}$ & $\begin{array}{l}\text { sound } \\
\text { categorie } \\
\mathrm{s}\end{array}$ & $\begin{array}{l}\text { sound } \\
\text { categories }\end{array}$ & $\begin{array}{l}\text { visual } \\
\text { categories }\end{array}$ \\
\hline Instructions & $\begin{array}{l}\text { Children } \\
\text { are told the } \\
\text { monster } \\
\text { wants them } \\
\text { to learn } \\
\text { the sounds } \\
\text { for her toys" }\end{array}$ & $\begin{array}{l}\text { Children } \\
\text { are told } \\
\text { to give } \\
\text { the } \\
\text { monster } \\
\text { his food } \\
\text { or drink } \\
\text { as fast as } \\
\text { they can }\end{array}$ & $\begin{array}{l}\text { Children } \\
\text { are told to } \\
\text { give the } \\
\text { monster } \\
\text { his food or } \\
\text { drink as } \\
\text { fast as they } \\
\text { can }\end{array}$ & $\begin{array}{l}\text { Children } \\
\text { are told to } \\
\text { give the } \\
\text { creature } \\
\text { his food or } \\
\text { drink as } \\
\text { fast as they } \\
\text { can }\end{array}$ \\
\hline Length of training & $\begin{array}{l}\text { Training } \\
\text { phase } \\
\text { contains } 24 \\
\text { trials before } \\
\text { evaluation of } \\
\text { performance } \\
\end{array}$ & $\begin{array}{l}\text { Training } \\
\text { phase } \\
\text { contains } \\
48 \text { trials }\end{array}$ & $\begin{array}{l}\text { Training } \\
\text { phase } \\
\text { contains } \\
48 \text { trials }\end{array}$ & $\begin{array}{l}\text { Training } \\
\text { phase } \\
\text { contains } \\
48 \text { trials }\end{array}$ \\
\hline Children's responses & $\begin{array}{l}\text { Children's } \\
\text { responses are } \\
\text { direct } \\
\text { interpretation } \\
\text { s of sounds }\end{array}$ & $\begin{array}{l}\text { Children } \\
\text { are not } \\
\text { required } \\
\text { to } \\
\text { interpret } \\
\text { sounds, } \\
\text { as } \\
\text { they can } \\
\text { wait and } \\
\text { respond } \\
\text { based on } \\
\text { the object } \\
\text { that } \\
\text { appears } \\
\text { on } \\
\text { the } \\
\text { screen }\end{array}$ & $\begin{array}{l}\text { Children are not } \\
\text { required to } \\
\text { interpret } \\
\text { sounds, as } \\
\text { they can wait } \\
\text { and respond } \\
\text { based on the } \\
\text { object that } \\
\text { appears on } \\
\text { the screen }\end{array}$ & $\begin{array}{l}\text { Children } \\
\text { are not } \\
\text { required to } \\
\text { interpret } \\
\text { visuals, as } \\
\text { they can } \\
\text { wait and } \\
\text { respond } \\
\text { based on } \\
\text { the object } \\
\text { that } \\
\text { appears on } \\
\text { the screen }\end{array}$ \\
\hline Contingency/Feedback & $\begin{array}{l}\text { Feedback } \\
\text { is contingent } \\
\text { on the child's } \\
\text { response }\end{array}$ & $\begin{array}{l}\text { No } \\
\text { feedback } \\
\text { is } \\
\text { provided }\end{array}$ & $\begin{array}{l}\text { Same as } \\
\text { the } \\
\text { previous } \\
\text { implicit } \\
\text { study }\end{array}$ & $\begin{array}{l}\text { Same as } \\
\text { the } \\
\text { previous } \\
\text { implicit } \\
\text { study }\end{array}$ \\
\hline
\end{tabular}

Table 1: Comparison of Task Designs in Four Experiments: Adapted from Quam et al. (in prep). 


\section{CHAPTER II: Experiment One: Implicit Sound Learning}

As mentioned previously, the current study included two experiments: Experiment One that examined children's implicit sound learning and Experiment Two that examined children's implicit visual learning. The current chapter describes the following three sections of Experiment One: 1) Methods (including procedure implemented in Experiment Two), 2) Results (including statistical design used in Experiment Two), and 3) Discussion.

\subsection{Methods}

\subsubsection{Participants}

Thirty participants were recruited in this study, including one Englishdominant child with DLD and 29 English-dominant children with TLD (see Table 2 for the children's demographic information). The English-dominance of the participants was determined based on reports from parent/caregiver questionnaires. The participants were recruited from private and public preschools and kindergartens in the Portland metro area. The agreement for the children to participate in the study was obtained from the participants' parents or caregivers via parental permission forms, along with children's verbal assent.

The inclusion criteria for the participants used in this study were the same as those used in Quam et al. (2020). All the participants passed a pure-tone audiometric screening that was conducted at 1000, 2000, and $4000 \mathrm{Hertz}(\mathrm{Hz})$ at 20 decibels in hearing level (dB HL) in both ears individually. In this study, the nonverbal subtests on the Kaufman Assessment Battery for Children 


\begin{tabular}{ccccc} 
& \multicolumn{3}{c}{ TLD group } & \multirow{2}{*}{ One child with DLD } \\
\cline { 2 - 4 } & Mean & SD & Range & \\
\hline Age (year; month) & $4 ; 9$ & 4 months & $4: 1-5 ; 6$ & $4 ; 5$ \\
\hline Primary Caregiver's Education (years) & 16 & 1.7 & $12-18$ & 16 \\
\hline KABC-II & 116.14 & 10.71 & $91-138$ & 98 \\
\hline SPELT-P2 & 121.7 & 7.7 & $94-131$ & 83 \\
\hline PPVT-4 & 125.76 & 12.91 & $96-142$ & 107 \\
\hline
\end{tabular}

Table 2: Demographic information and standardized test scores for children with TLD and one child with DLD.

(KABC-II; Kaufman and Kaufman, 2004) were used to screen a child's cognitive skills. All the participants received a composite score of 75 or above on the nonverbal subtests of KABC-II, indicating the participants' nonverbal intelligence being in the normal range. Structured Photographic Expressive Language Test Preschool: 2nd Edition (SPELT-P2; Dawson et al., 2005) was administered to screen the participants' expressive English language skills. In this study, one child that received a score of below 87 on the SPELT-P2 was included in the DLD group, and children who received a score of at least 87 on the SPELT-P2 were included in the TLD group. A cutoff score of 87 has been previously shown to provide the highest sensitivity and specificity (Greenslade et al., 2009). The Peabody Picture Vocabulary Test (PPVT-4; Dunn et al., 2007) was also administered to characterize children's broader language profile. Also see Table 2 for a summary of the screening results of the participants.

In the recruitment stage, if any concerns about a child's articulation skills were raised from parent and teacher reports or the experimenters, the SoundsIn-Words section of the Goldman-Fristoe Test of Articulation 2 (GFTA 2; Goldman et al., 2000) was administered. In addition, for children who scored 
below the SPELT-P2 cutoff score of 87, any items on the SPELT-P2 that could have been missed due to their possible limited capacity to articulate the sounds were re-scored as correct, as a way to examine if the child's SPELT-P2 score was still below the cutoff score even after accounting for speech sound production skills. Caregiver questionnaires were used to exclude children that were reported to have a history of any of the following concerns: brain injuries, uncorrected vision concerns, and mobility restrictions that may affect a child's capacity to participate in the experiments.

\subsubsection{Sound Stimuli}

By modifying the sound stimuli generated in Quam et al. (2020), Experiment One used synthesized isolated vowels mimicking vowels [i] and $[u]$ as sound stimuli, which were synthesized via the KlattGrid speech synthesizer (Klatt and Klatt, 1990; Weenink, 2009) installed in Praat (Boersma and Weenink, 2008).

Two types of sound categories were constructed in Experiment One: pitchand duration(i.e., vowel length)-differentiated categories. For each sound category, two dimensions were used to define pitch or duration: high-pitch vs. low pitch, long- duration vs. short-duration. In one of the two sound categories, each dimension includes three different sounds, resulting in 6 sounds in total for each condition: In the pitch condition: high- pitch1, high-pitch2, highpitch3; low-pitch1, low-pitch2, low- pitch3. In the duration condition: shortduration1, short-duration2, short-duration3; long-duration1, long-duration2, long-duration3. Pitch and duration values for sound stimuli are shown in Figure 1.

Pitch stimuli used in Experiment One were distributed along a 
continuum de-fined in semitones. By manipulating the second-formant frequency (F2), the pitch stimuli were made to mimic the vowel /u/, while the duration stimuli were generated to mimic the vowel/i/. As mentioned previously, Quam et al. (2020) found out that both children with DLD and children with TLD had more difficulty with discriminating duration differences in sounds than discriminating pitch differences in sounds. Therefore, in the process of re-synthesizing pitch and duration categories in Experiment One, both sound dimensions were made to be more comparable as the difference between the two sound categories (pitch vs. duration) were enlarged, and

Duration categories:

/i/ vowel

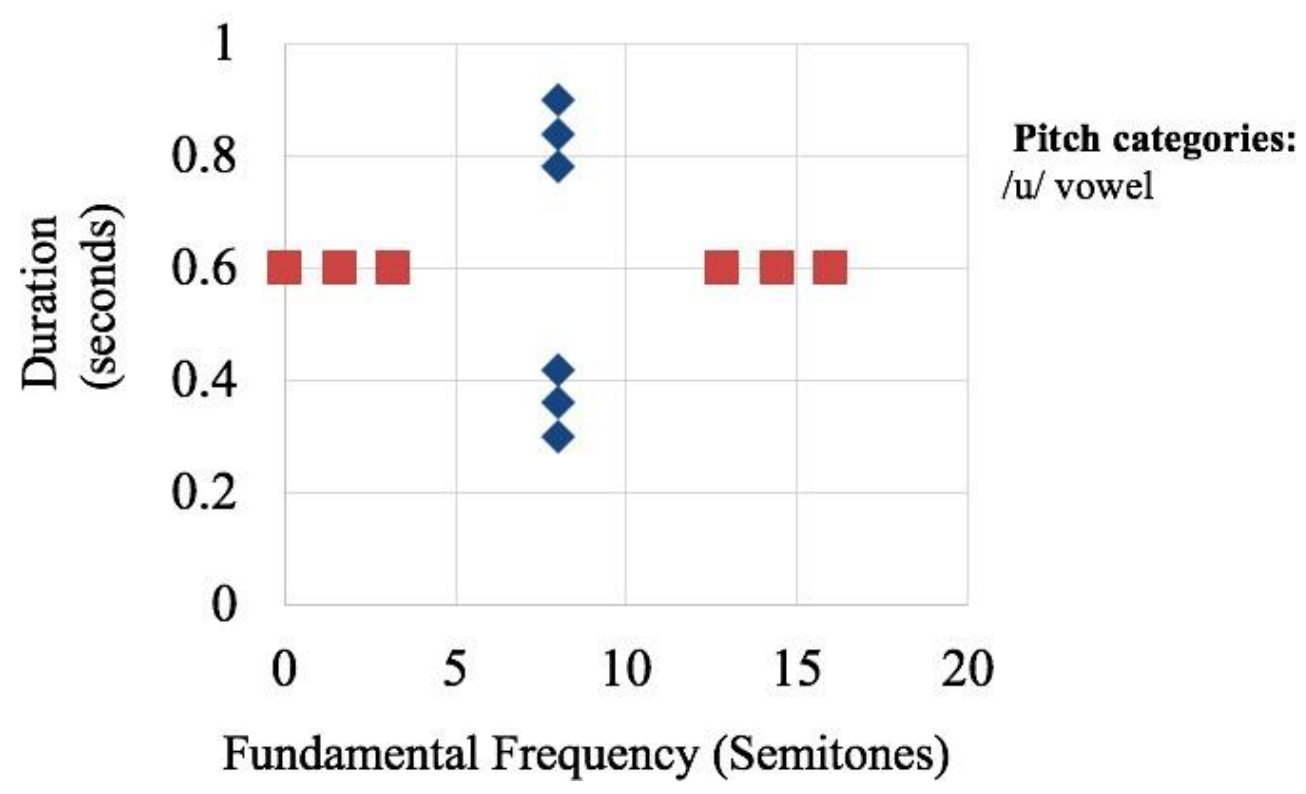

Figure 1: Duration (in seconds) and pitch (in semitones) for the 12 auditory stimuli used in Experiment One: Adapted from Quam et al. (2019).

more irrelevant variation in vowel quality was added: the F2 of the vowels was changed to make some of the pitch stimuli more like the vowel/i/ and some of the duration stimuli more like the vowel $/ \mathrm{u} /$. 


\subsubsection{Apparatus and Procedure}

Both Experiment One and Experimented Two were created and conducted via the PsychoPy program (Peirce, 2007). Each participant completed four computer-based experiments: one explicit sound-learning experiment, one explicit visual-learning experiment, one implicit sound-learning experiment, and one implicit visual-learning experiment.

To reduce contamination across tasks, we planned to avoid having one child finish two experiments in the same domain on the same day (e.g., two visual experiments on the same day or two auditory experiments on the same day) or finishing two implicit/explicit experiments on the same day. However,

due to incidental errors, five children in the TLD group completed two visual experiments on the same day, and one of them also completed two auditory tasks on another day.

Two implicit learning experiments, the test of implicit mapping of sounds to objects, the test of implicit mapping of visuals to objects, are reported in the current study. The two explicit learning experiments will be reported elsewhere.

\subsubsection{Sound-Discrimination Task}

The procedure of conducting a sound-discrimination task was similar to that con- ducted in Quam et al. (2020).

Children were randomly assigned to learn pitch-contrasted or durationcontrasted sounds in the implicit-learning experiment (and, therefore, learned the other type of sounds in the explicit-learning experiment). Before they started learning the sounds, each of them was asked to complete a sound 
discrimination task, which was designed to obtain the baseline of their sensitivity to the same sound dimension they would learn in the mapping task. Before Experiment One started, the one child with DLD and 12 children with TLD had participated in an explicit sound-learning experiment (to be reported elsewhere), 17 children with TLD had not participated in any explicit soundlearning experiment. In the sound-discrimination task in Experiment One, one child with DLD and 14 children with TLD listened to pitch-differentiated sounds, and 15 children with TLD listened to duration-differentiated sounds. In future analyses, data from all children for both auditory cues will be reported (data from the explicit

experiments will be reported elsewhere.).

For the sound-discrimination task in Experiment One, children heard 12 pairs of sounds from a set of 6 sound stimuli (contrasting in pitch or duration) that are part of a continuum, including sounds differing from each other acoustically in 1-5 steps (Again, see Figure 1), resulting in 12 trials in total. For each sound pair, one sound was always one of the two sounds at the end of the continuum. Another sound was either the same or differed by a number of step(s) on the continuum from the endpoint sound.

In each of the 12 trials, a child heard two sounds. They were told to listen to both sounds and say "same" or "different," depending on whether they thought the two sounds were identical or not. The experimenter recorded the child's every response by pressing the button "S" on the keyboard for "same" and "D" for "different." Following the procedure in Quam et al. (2020), the children's responses were transformed to d-prime scores (see Statistical Design below for more details) to measure children's sensitivity to the sound differences in the pitch or the duration sound categories. Consistent with the 
research interests stated in Quam et al. (2020), in the current study, we still planned to investigate whether children's sensitivity to sound differences varies across cues (pitch vs. duration) and whether the changes of children's sensitivity to sound differences correspond to the changes of the acoustic distance between two sounds.

\subsubsection{Implicit Sound-Meaning-Mapping Task}

After the sound-discrimination task where children heard pitch- or duration- differentiated sounds, children participated in an implicit soundmeaning mapping task where they learned to map the same six sounds they heard in the sound- discrimination task to objects: The one child with DLD and 14 children with TLD learned pitch-differentiated sounds, and 15 children with TLD learned duration-differentiated sounds.

The implicit sound-meaning-mapping task was created to encourage children to listen to sounds and implicitly learn to link the sounds to objects. There were some similarities and differences between the implicit-learning task design and the explicit learning task design (again, see Table 1 for comparison among the current study and the previous two studies). First,

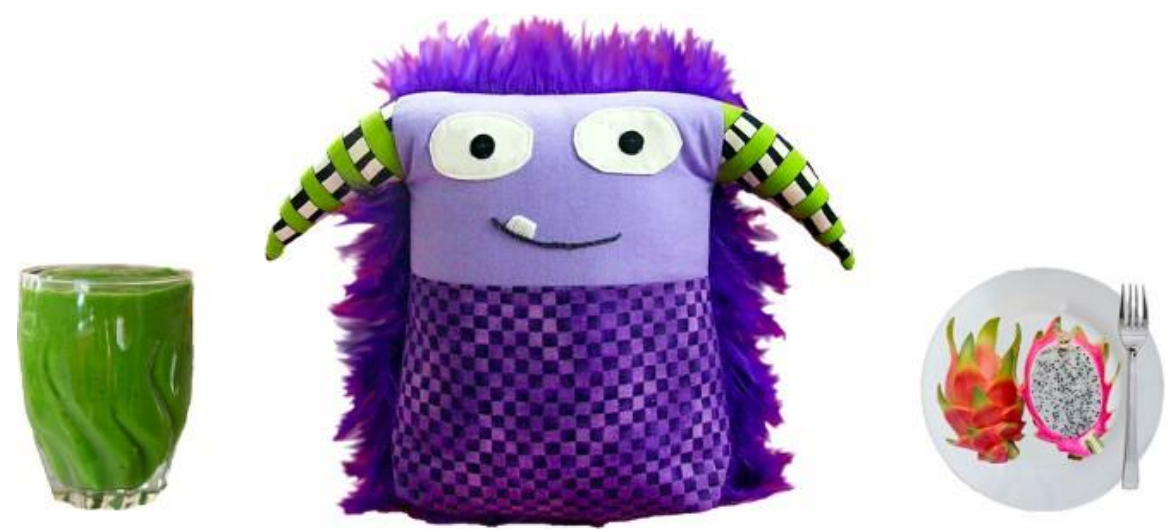

Figure 2: Either Leonard's favorite drink (left) or his favorite food (right) appears on the screen after a delay (Quam et al.,in prep). 
similar to the task scenario set in Quam et al. (2020), in the task familiarization phase that helped the children to understand what they would be doing, a monster named "Leonard" was introduced to the children. Children were told that Leonard "talks in a funny way," and he wants to show the children his favorite food and his favorite drink (See Figure 2).

Second, in the familiarization phase, the experimenter told the children that Leonard "has some special sounds for his food," and then pointed to the food icon attached with Velcro attached to the right arrow key on the keyboard and told the children that Leonard "has some special sounds for his drink" and then pointed to the drink icon attached with Velcro to the left arrow key on the keyboard. After that, two pictures showing Leonard's favorite food and his favorite drink were presented on the screen (again, see Figure 2). Then children were told that if Leonard "wants the drink, he will make his sound for drink, and it will magically appear" inside a box on the screen the experimenter was pointing to. The experimenter explained to the children that the "drink on the screen is the same as the one on the keyboard," while pointing to the drink picture on the screen and then the drink icon on the keyboard. The experimenter also told the children that once they "see the drink," they should "press the button as fast as [they] can to give it to him (Leonard)." In contrast to the prior explicit study where children used the button to make an explicit categorization of the sound, Experiment One allowed children to wait until the object appeared and then just press the button that matched it, which was much more passive.

Third, children in the current study did not receive explicit feedback as in the explicit learning studies (in which they saw a smiley face if they chose the 
correct object and a frowny face for the incorrect object). Instead, in the training phase of the implicit sound-meaning-mapping task, the correct object would appear on the computer screen a few milliseconds after a sound was played regardless of which arrow key the children pressed. In other words, even if a child did not press either of the arrow keys, the correct object would still show up on the screen. The experimental design in the current study contrasted with the previous implicit study in having the object appear in a stationary location on the screen instead of scooting in from the side.

In the familiarization phase, children also had the chance to practice pressing the left arrow key and the right arrow key on the keyboard to match the pictures of the drink and the food they saw on the screen. They were asked, “He(Leonard)'s hungry for more food! What do you press?" and "Now, if he wants his drink again, what button do you push?" In order to move on to the learning phase, the experimenter made sure that the children could press the correct button in response to the prompt.

The main section of Experiment One included two training blocks and one test block. Each block had 24 trials, resulting in 72 trials in total.

Six sounds from the continuum were played four times for each block. In the training blocks, children heard each sound on the continuum, pressed the left or right arrow key to feed Leonard's favorite drink or his favorite food, and saw the correct object appearing on the screen (or they could wait until after seeing the object to press the button).

Before starting the test block, children were notified with emphasis that "This time the food or drink will NOT magically appear until you make a choice." Children were also reinforced for the first few choices they correctly made with verbal praise, "You got it!" Following the similar procedure in 
Quam et al. (2020), children's responses were saved and then compared to the correct answers by the PsychoPy program (Peirce, 2007), as the three lowpitched or short-duration sounds matching one object, and the three highpitched or long-duration sounds matching another object. Every child's percentage of correct responses was computed for training block one, training block two, and the test block. The accuracy scores of the training blocks were to make sure children were on task.

After finishing the test block, children participated in a production task where they were asked, "Now, can you tell me what sound Leonard makes when he wants his food/drink?"

\subsection{Results}

\subsubsection{Statistical Design}

Approaches to data analyses in both Experiment One and Experiment Two are described below.

\subsubsection{Data Analysis of the Performance of Children with TLD}

In the analysis of discrimination data, in order to examine how children with TLD were sensitive to the sound and visual stimuli, we used d-prime scores which were calculated as the difference between the z-scores of $H$ (hit rates) and $F \quad$ (false alarm rates): $d^{\prime}=z(H)-z(F)$. H was the proportion of the number of "different" responses to the number of trials where two sounds or the visual representation of two creatures differed. $F$ was the proportion of the number of "different" responses tothe numberof trials where the two sounds were the same, or the visual representation of two creatures 
was the same. It was important to note that the same False Alarm rate was used for each distance (i.e., each distance has a different Hit rate) and that there was a different d-prime score for each child for each distance on the continuum (15). The higher a child's d-prime scores are for one dimension (pitch or duration; legs or tail) of the sounds they heard or the visual images they saw, the more sensitive the child is to the dimension (pitch or duration; legs or tail).

In addition, in order to conduct inferential statistics on data collected from both the discrimination task and the stimuli-meaning-mapping task completed by children with TLD, we used factorial multivariate analyses of variance (MANOVAs) rather than univariate analyses of variance (ANOVA). This was to follow the procedure stated in Quam et al. (2020) that addressed the violation of sphericity: For example, in preliminary ANOVAs on discrimination data in the previous study, results of Mauchly's Test of Sphericity for the main effect of Distance on the Continuum indicated that the assumption of sphericity had been violated (Mauchly's $W=0.30, p$ <.001). In the current study, Mauchly's Test of Sphericity in a preliminary test to the ANOVA on visual discrimination data also indicated that the assumption of sphericity had been violated (Mauchly'sW $=0.257, p<$ $.001)$.

In the current study, a violation of the assumption of normality was also identified. In preliminary MANOVAs on sound discrimination data, the Shapiro-Wilk tests of normality across five distances indicated that residuals were not normally distributed. Residuals were calculated for the MANOVAs for each distance and then reported in Shapiro-Wilk tests of normality. Significant non-normality was suggested for the following distances in Experiment One: Auditory d-prime score for Distance $3(W(29)=.887, p=$ 
$.005)$, Auditory d-prime score for Distance $5(W(29)=.926, p=.044)$. In addition, significant non-normality was also found in the visual discrimination data for the following conditions: Visual d-primes score for Distance 2 ( $W$ $(29)=.918, p=.028)$, Visual d-prime score for Distance $3(W(29)=.954, p$ $=.001)$, Visual d-prime score for Distance $4(W(29)=.868, p=.002)$, and Visual d-prime score for Distance $5(W(29)=.793, p<.001)$.

Furthermore, visual examination of residuals on histograms indicated that residuals for discrimination data were left-skewed for Distances 3 and 5 (others such as Distance 2 were not clearly left-skewed) in Experiment One and overall left-skewed for the distances that showed a violation of normality assumption in Experiment Two. However, a square transform would not be appropriate because it would remove the distinction between positive and negative numbers, which shows a meaningful distinction for d-prime scores (positive d-prime scores show more sensitivity to stimuli than negative dprime scores). In order to address the non-normality of dependent variables, besides using parametric tests (t-tests), we plan to run non-parametric permutation tests in the future because permutation tests do not require normality (Legendre and Legendre, 1998).

To address the non-normality of the data in both experiments in the future, we will conduct a Fisher-Pitman permutation test where the difference in means of two groups will first be calculated to double-check that the results are still significant in a test that does not assume normality. Furthermore, given that ANOVA/MANOVA is fairly robust to non-normality (Quam et al., 2017b), we will still use MANOVA and MANCOVA for some of the data analyses.

The statistical design of analyzing data in the mapping tasks is described 
as follows: Accuracy data in the test blocks of stimuli-meaning-mapping tasks were analyzed with the use of MANOVAs. Reaction time in the mapping tasks was also analyzed via MANOVAs in the training blocks and the test block. Preliminary MANOVAs on reaction time data indicated that some distributions of residuals were normally distributed (e.g., auditory reaction time for the training blocks), some data were not normally distributed and not clearly right-tailed (e.g., auditory reaction time for the test block), and some distributions were clearly right-tailed. Therefore, it is not appropriate to conduct log-transformation on all the reaction time data because logtransformation is only appropriate for right-skewed data. Given that permutation tests are planned to be conducted on data in the discrimination tasks in the future, in order to use a consistent analytical approach, we will also conduct non-parametric permutation tests on reaction time data in the mapping tasks in the future.

In order to relate discrimination scores and mapping tasks, we conducted multivariate analyses of covariance (MANCOVAs).

\subsubsection{Data Analysis of the Performance of the One Child with DLD}

For data of the only child with DLD, descriptive statistics were used to present the performance of the child on discrimination and mapping tasks and compare it with the performance of the children with TLD.

\subsubsection{Sound Discrimination}

Children with TLD

MANOVA was conducted to investigate how d-prime scores were affected 
by the between-subjects predictors Cue (pitch vs. duration) and First Task (pitch- first vs. duration-first) and the within-subjects predictor Distance on the Continuum (steps 1-5). The MANOVA revealed a significant main effect of Distance $($ Wilks' $\Lambda=.512, F(4,22)=5.233, p=.004)$.

To further examine the main effect of Distance, planned multiple comparison tests (paired t-tests) between adjacent distance pairs were conducted. To reduce the Type I error rate, we planned that the t-tests were

\begin{tabular}{|c|c|c|c|c|c|c|}
\hline & 1 & 2 & 3 & 4 & 5 \\
\hline \multirow{3}{*}{$\begin{array}{l}\text { D-prime } \\
\text { Scores } \\
\text { Overall } \\
\text { (TLD) }\end{array}$} & mean & 1.598 & 1.385 & 2.557 & 3.516 & 3.303 \\
\hline & SD & 2.815 & 3.154 & 3.510 & 2.828 & 2.970 \\
\hline & Range & $\begin{array}{l}(-6.18- \\
6.18)\end{array}$ & $\begin{array}{l}(- \\
6.18- \\
6.18)\end{array}$ & $\begin{array}{l}(- \\
6.18- \\
6.18)\end{array}$ & $\begin{array}{l}(- \\
3.09- \\
6.18)\end{array}$ & $\begin{array}{l}(- \\
3.09- \\
6.18)\end{array}$ \\
\hline \multirow{3}{*}{$\begin{array}{l}\text { D-prime } \\
\text { scores } \\
\text { for Pitch } \\
\text { (TLD) }\end{array}$} & mean & 1.104 & 1.324 & 3.973 & 4.413 & 3.973 \\
\hline & SD & 2.302 & 2.897 & 3.519 & 2.897 & 3.073 \\
\hline & Range & $\begin{array}{l}(- \\
3.09- \\
6.18)\end{array}$ & $\begin{array}{l}(- \\
3.09- \\
6.18)\end{array}$ & $\begin{array}{l}(- \\
3.09- \\
6.18)\end{array}$ & $\begin{array}{l}(- \\
3.09- \\
6.18)\end{array}$ & $\begin{array}{l}(- \\
3.09- \\
6.18)\end{array}$ \\
\hline $\begin{array}{l}\text { D-prime } \\
\text { scores } \\
\text { for Pitch } \\
\text { (DLD) }\end{array}$ & mean & 0 & 0 & 6.18 & 3.09 & 6.18 \\
\hline \multirow{3}{*}{$\begin{array}{l}\text { D-prime } \\
\text { scores } \\
\text { for } \\
\text { Duration } \\
\text { (TLD) }\end{array}$} & mean & 2.060 & 1.442 & 1.236 & 2.678 & 2.678 \\
\hline & SD & 3.234 & 3.478 & 3.046 & 2.576 & 2.829 \\
\hline & Range & $\begin{array}{l}(- \\
6.18- \\
6.18)\end{array}$ & $\begin{array}{l}(- \\
6.18- \\
6.18)\end{array}$ & $\begin{array}{l}(- \\
6.18- \\
6.18)\end{array}$ & $\begin{array}{l}(.00- \\
6.18)\end{array}$ & $\begin{array}{l}(- \\
3.09- \\
6.18)\end{array}$ \\
\hline
\end{tabular}

Table 3: Auditory d-prime scores across five distances for children with TLD (mean, standard deviation, and range) and one child with DLD (mean).

Bonferroni corrected. The tests revealed that d-prime scores were not significantly different for any of the adjacent distance pairs. While the pvalues for the following two adjacent distance pairs were both less than 0.05 : 
$(p<0.0125):$ Distance 2 and Distance $3(p=0.039)$, Distance 3 and Distance $4(p=0.048)$, they did not reach the $\mathrm{p}$-value threshold for Bonferroni correction. Table 3 shows the mean and standard deviation of auditory d-prime scores across five distances for children with TLD and the d-prime scores for the performance of the one child with DLD.

A significant interaction of Distance on the Continuum (steps 1-5) by Cue (pitch vs. duration) was also found $($ Wilks' $\Lambda=.545, F(4,22)=4.594$, $p=.008)$. To examine the interaction, we conducted planned multiple comparison tests (paired t-tests) for each Cue between adjacent distances, following a similar procedure as reported above for the examination of the main effect of Distance. Four distance pairs within each cue were Bonferroni corrected. The tests revealed that for pitch data, d-prime scores were significantly higher for Distance 3 than for Distance 2 $(t(13)=-3.710, p=0.003)$, and there was no significant difference in d-prime scores for the rest of the adjacent distance pairs within the pitch cue. For duration data, there was no significant difference in d-prime scores for any of the adjacent distance pairs. While the p-value for the comparison of Distance 2 and Distance 3 was less than $0.05(p=0.048)$, it did not reach the $\mathrm{p}$-value threshold for Bonferroni correction $(p<0.0125)$. Again, see Table 3 for the mean and standard deviation value for the d-prime scores of the performance of the children with TLD.

Additional MANCOVAs were conducted to examine whether Age, Gender, or Primary Caregiver Education affected the participants' performance on auditory dis- crimination tasks. The main effect of Distance remained significant in the model including Age $\left(W_{i l k s}^{\prime} \Lambda=.434, F(4,21)=\right.$ $6.844, p=.001)$ and became non-significant in the models including Gender 
$($ Wilk' $\Lambda=.816, F(4,21)=1.186, p=.346)$ and Primary Caregiver Education $($ Wilks' $\Lambda=.679, F(4,20)=2.363, p=.088)$. In the previous study, MANCOVAs including primary caregiver education revealed no significant effects, either. However, the MANCOVAs in Experiment One only included children with TLD, while the MANCOVAs in the previous study included both children with and without DLD. The interaction of Distance on the Continuum (steps 1-5) by Cue (pitch vs. duration) remained significant in the models including Age $($ Wilks' $\Lambda=.532, F(4,21)=4.610, p=.008)$, Gender $($ Wilks' $\Lambda=.549, F(4,21)=4.313, p=.011)$, and Primary Caregiver Education $($ Wilks' $\Lambda=.472, F(4,20)=5.600, p=.003)$. In the model that included Age, there was an additional interaction of Distance by Age $\left(W_{i l k s}^{\prime} \Lambda=.472, F(4,21)=5.865, p=.002\right)$.

To further investigate the interaction of Distance by Age, we calculated the median age of the children with DLD $(4 ; 9 ; 10$, year/month/day) and split the data into two groups with one group including children who were younger than $4 ; 9 ; 10$ and the other group including those who were not younger than $4: 9 ; 10$. We conducted correlation tests between age and the average scores of the d-prime scores across five distances. The tests revealed that there was a positive correlation between age and d-prime scores at Distance 1 ( $r=.327, p$ $=.083$ ), a positive but negligible correlation between age and d-prime scores at Distance $3(r=.089, p=.0613)$, and other distances showed opposite directions, showing negative correlations between age and d-prime scores. However, none of the associations reached the p-value threshold for Bonferroni correction $(p<.0125)$.

One Child with DLD

The pitch d-prime score of the child with DLD for each distance fell within 
the range of the pitch d-prime score of children with TLD for each distance and was within $1 \mathrm{SD}$ (standard deviation) from the mean of the pitch d-prime scores of children with TLD (again, see Table 3).

\subsubsection{Implicit Sound-Meaning Mapping}

\section{Children with TLD}

The accuracy of the sound-meaning-mapping of children with TLD was computed. To examine children's implicit learning of sounds differing in pitch and duration, a MANOVA was conducted including between-subject predictors Cue (pitch vs. duration) and First Task (pitch-first vs. durationfirst), the within-subject predictor Phase in the Test Block (phase one vs. phase two), and the dependent variable Accuracy Scores in the test block. The MANOVA revealed that there was a significant effect of Cue (pitch vs. duration) on sound-meaning mapping accuracy $(F(1,25)=5.502, p=$ .027), indicating that children with TLD learned pitch categories $(M=$ $67.0 \%, S D=.205)$ significantly better than duration categories $(M=$ $49.7 \%, S D=.140)$.

To compare the reaction time in two training blocks, we conducted a MANOVA including the between-subjects predictors Cue (pitch vs. duration) and First Task (pitch-first vs. duration-first), the within-subject predictor Training Block (one vs. two), and the dependent variable Reaction Time in training blocks. The MANOVA revealed a significant effect of Cue (pitch vs. duration) $(F(1,25)=5.869, p=.023)$, reflecting that children who learned pitch category in the training blocks $(M=2.828 \mathrm{sec}, S D=0.368)$ reacted to the sounds significantly faster than those who learned duration category in the 
training blocks $(M=3.104 \mathrm{sec}, S D=0.435)$. No significant effects of phase were found, which suggested that children with TLD did not speed up over the course of the training phase.

To compare the reaction time in the two phases of the test block, we conducted a MANOVA including the between-subjects predictors Cue (pitch vs. duration) and First Task (pitch-first vs. duration-first), the within-subject predictor Phases in the Test Block (one vs. two), and the dependent variable Reaction Time in the Test Block. The MANOVA revealed a significant main effect of Phase $($ Wilks' $\Lambda=.831, F(1,25)=5.089, p=.033)$, indicating that children with TLD reacted to the sound stimuli significantly faster in the second half $(M=2.419 \mathrm{sec}, S D=1.793)$ of the test block than in the first half $(M=3.064 \mathrm{sec}, S D=1.770)$ of the test block. There could be a concern that children might learn from the implicit feedback provided in the test block, i.e., that after their button press, an object appears that either matches or mismatches it. This does not necessarily indicate learning over the test block because the accuracy score does not significantly increase. Instead, it could indicate increasing familiarity with the procedure.

\section{One Child with DLD}

The child with DLD learned the pitch category and completed the implicit sound- meaning task with $100 \%$ accuracy of learning. The child's reaction time to stimuli in the second training block $(2.90 \mathrm{sec})$ was faster than that in the first training block $(3.09 \mathrm{sec})$. The child's reaction time to stimuli was also faster in the second phase of the test block $(1.89 \mathrm{sec})$ than that in the first phase of the test block $(3.04 \mathrm{sec})$.

The accuracy score of the child with DLD (100\%) on the pitch learning task fell beyond the range of the accuracy data for children with TLD (see 
Table 4). The average reaction time of the child with DLD was 2.999 seconds in the two training blocks and 2.463 seconds in the test block. Compared to the pitch data for children with TLD, the reaction time of the child with DLD was within $1 \mathrm{SD}$ above the mean of the reaction time of children with TLD in the training blocks, and within 1 SD below the mean of the reaction time of children with TLD in the test block (See Table 5). 


\begin{tabular}{|l|l|l|l|}
\hline Cue & Mean & $\begin{array}{l}\text { Standard } \\
\text { deviation }\end{array}$ & Range \\
\hline Pitch & $\begin{array}{l}\text { 67.0\%(One } \\
\text { child with } \\
\text { DLD: } 100 \%)\end{array}$ & .205 & $\begin{array}{l}(41.7 \%- \\
95.8 \%)\end{array}$ \\
\hline Duration & $49.7 \%$ & .140 & $\begin{array}{l}(20.8 \%- \\
66.7 \%)\end{array}$ \\
\hline
\end{tabular}

Table 4: Accuracy of the auditory mapping of children with TLD and one child with DLD

\begin{tabular}{|l|l|l|l|l|}
\hline Cue & Block & Mean & $\begin{array}{l}\text { Standard } \\
\text { deviation }\end{array}$ & Range \\
\hline Pitch & Training & $\begin{array}{l}2.828 \text { (One } \\
\text { child with } \\
\text { DLD: } \\
2.999)\end{array}$ & .368 & $\begin{array}{l}(2.291- \\
3.474)\end{array}$ \\
\cline { 2 - 6 } & Test & $\begin{array}{l}2.296 \text { (One } \\
\text { child with } \\
\text { DLD: } \\
2.463)\end{array}$ & .844 & $\begin{array}{l}(1.292- \\
3.828)\end{array}$ \\
\hline \multirow{2}{*}{ Duration } & Training & 3.104 & .435 & $\begin{array}{l}(2.409- \\
4.239)\end{array}$ \\
\cline { 2 - 6 } & Test & 3.072 & 2.071 & $\begin{array}{l}(1.420- \\
10.007)\end{array}$ \\
\hline
\end{tabular}

Table 5: Reaction time (seconds) of the auditory-mapping of children with TLD and one child with DLD

\subsubsection{Linking Sound Discrimination and Implicit Sound-Meaning Mapping}

Children with TLD

Multivariate analyses of covariance (MANCOVAs) were conducted to examine the association between sound discrimination scores and the accuracy of sound learning among children with TLD. The MANCOVAs 


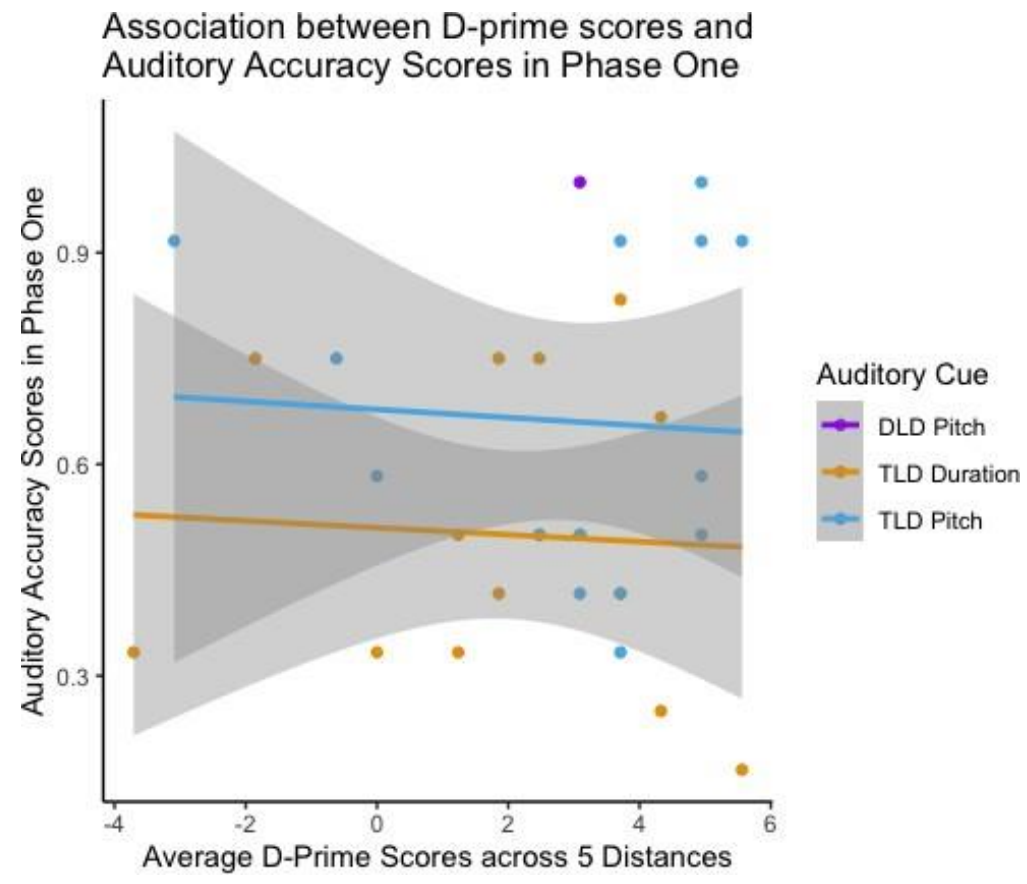

Figure 3: Association (with 95\% confidence intervals) between Sound Discrimination and Mapping in Phase One of the Test Block.

included Cue (pitch vs. duration), First Task (pitch-first vs. duration-first), and Phase in the Test Block (phase one vs. phase two) as categorical predictors, and D-Prime Score as a continuous predictor. Following the same procedure in Quam et al. (2020), the D-Prime score was simplified and calculated in two ways. First, D-Prime Score was calculated as the average of d- prime scores across five distances. Second, D-Prime Score was included as the d-prime score from Distance 5. Both models revealed that there was no significant effect of the d-prime score on sound-meaning-mapping accuracy, indicating that there was a lack of association between sound discrimination scores and sound-meaning-mapping accuracy. A significant effect of Cue (pitch vs. duration) was found in both model one $((F(1,24)$ $=4.715, p=.040))$ and model two $((F(1,24)=.4 .550, p=.043))$, which replicated the original model on sound accuracy and indicated that 


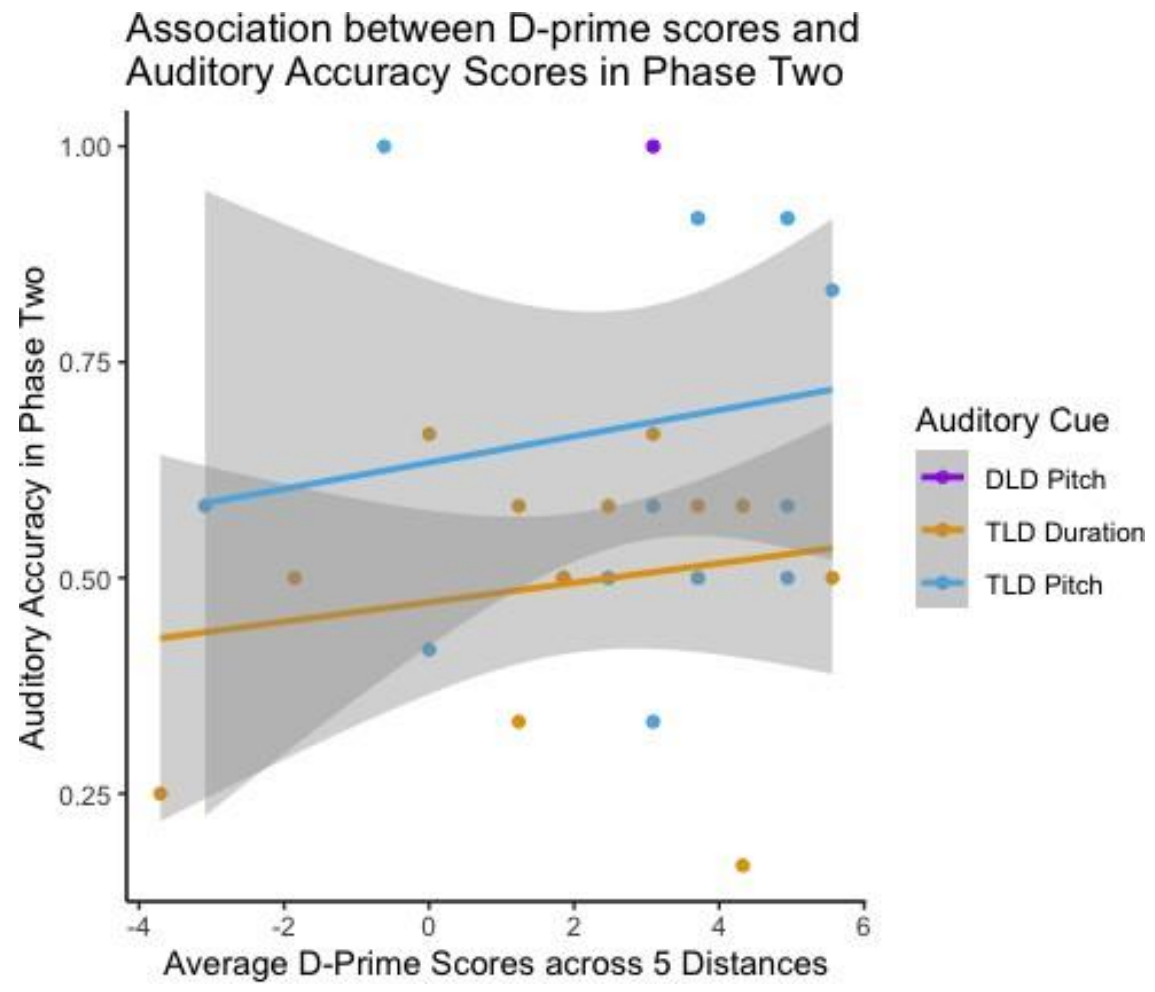

Figure 4: Association (with 95\% confidence intervals) be- tween Sound Discrimination and Mapping in Phase Two of the Test Block.

including covariates did not account for the difference between pitch and duration.

Following the same procedure in Quam et al. (2020), we conducted simple Pear- son's correlation tests to further examine the relationship between sound discrimination and sound-meaning mapping. A significant interaction with phase in Experiment Two was found and for maximum comparability between the two experiments, in Experiment One we first split the data by phase. The correlation between mapping accuracy and the average d-prime scores across five distances was positive for both phase one $(r=.013 ., p=.947)$ and phase two ( $r=.240, p=.209)$, although the positive correlation for phase 1 was 
negligible. Second, following the procedure in Quam et al. (2020), we also split the data by cue. The correlation between mapping accuracy and the average d-prime scores across five distances was positive but neg- ligible for both the pitch categories $(r=.058, p=.843)$ and the duration categories $(r=.055, p=.846)$. Overall, there was a positive correlation between mapping ac- curacy and the average d-prime scores across five distances $(r$ $=.137, p=.480$ ).

\section{One Child with DLD}

Figures 3 and 4 depict the relationship between the average d-prime scores across five distances and auditory mapping accuracy scores in two phases of the test block for children with TLD, as well as two data points that represent the performance of the child with DLD. The child with DLD learned the pitch category, and their performance was not falling on the regression line that approximated the performance of children with TLD who learned pitch categories. In other words, the pitch mapping accuracy of the child with DLD is very high compared with their pitch discrimination score, which is more average. Given that the upper limit to d-prime scores is 6.18 and the average d-prime score of the child with DLD (3.09) is not at the ceiling like their accuracy score is, the performance of the child with DLD is falling off the regression line.

\subsection{Discussion}

Experiment One provided evidence that the auditory discrimination sensitivity of children with TLD varied depending on the distance between the 
two sounds they heard, although no significant difference of the children's discrimination sensitivity was specifically found among any of the distance pairs. In addition, it was found that the variation of discrimination sensitivity of children with TLD differed in each cue, depending on the distance between the two sounds they heard. MANCOVAs including age revealed that the variation of discrimination sensitivity of children with TLD differed in children's age, depending on the distance between the two sounds they heard. When two sounds were one distance or three distances apart from each other, children in the older age group tended to have higher discrimination sensitivity than those in the younger age group. However, the association was not significant.

Experiment One also demonstrated that children with TLD learned sounds differing in pitch better than sounds differing in duration. In addition, children with TLD who learned the pitch categories reacted to stimuli faster than those who learned the duration categories. This indicates the children's advantage of learning pitch for the accuracy model and the reaction time model. This is consistent with the children's advantage of learning pitch found in the previous explicit study (Quam et al., 2020), although the previous study only investigated the accuracy, not the reaction time. Furthermore, children with TLD responded to the stimuli faster in the second half of the test phase than in the first half of the test phase. This pattern was also found in the performance of the child with DLD. Given that no significant effect of phase in the Test Block was found on the accuracy of the sound-meaning-mapping for children with TLD, we argued that the reaction time difference in the phases of the Test Block was likely due to children becoming used to the procedure over the course of the Test Block. However, it was also possible that 
their getting faster in the second phase of the Test Block indicates sound learning. This could be a concern because children's learning across the test phase could reflect explicit learning from the feedback rather than implicit learning as the task was designed. In other words, it could indicate a potential experimental-design flaw when children used more of their explicit learning skills in an experiment that was designed to test their implicit learning.

There was a lack of evidence that sound discrimination scores were associated with later sound learning for children with TLD in Experiment One, which did not replicate the association between sound discrimination and explicit sound-meaning mapping for participants with and without DLD found in Quam et al. (2020). Three possible reasons may help explain why there was a lack of association between sound discrimination scores and soundmeaning-mapping accuracy in Experiment One: First, it could be that the sample size was not large enough to have adequate statistical power to find an association. Power analyses revealed that at least 108 participants would be needed to yield a significant association between overall sound-meaningmapping accuracy and d-prime score of distance 5. Second, it could also be that there was a difference between explicit and implicit tests, given that the previous study examined explicit learning and Experiment One examined implicit learning. Third, it could be that the lack of association between sound discrimination and implicit sound-meaning mapping in Experiment One was not just a power issue, but also reflected less variance of the data, as only one child with DLD had been recruited in the study so far.

In Experiment One, the pitch discrimination sensitivity of the child with DLD was comparable to the pitch discrimination sensitivity of children with TLD, and the child's performance on the implicit pitch learning task was better 
than that of the average performance of children with TLD, with $100 \%$ accuracy of learning.

According to our prediction based on the PDH (Ullman and Pierpont, 2005) and the auditory-processing-deficit hypothesis (Merzenich et al., 1996; Tallal et al., 1996; Wright et al., 1997), children with DLD would show difficulty with sound implicit learning. Therefore, conducting Experiment Two with visual stimuli would help us further test the auditory deficit hypothesis to see if children with DLD (in the current study: the one child with DLD) would show less difficulty with implicit visual learning than with implicit sound learning. 


\section{CHAPTER III: Experiment Two: Implicit Visual Learning}

In order to further test the auditory processing deficit hypothesis, we conducted Experiment Two to investigate implicit visual learning among children with and with- out DLD, in comparison to children's implicit sound learning. The current chapter describes the following three sections of Experiment Two: 1) Methods, 2) Results, and 3) Discussion.

\subsection{Methods}

\subsubsection{Visual Stimuli}

The visual stimuli used in Experiment Two involved two groups of "creatures" named "Greebles" (singular: Greeble; see Figure 5, left) and "Timbos (singular: Timbo, see Figure 5, right)." The visual stimuli were based on images shared by Daniel Swingley that were in turn based on the work of Younger (1985). Within each group, the creatures differ from each other based on one attribute. Greebles differ from each other in the thickness of the tail, and Timbos differ from each other in the length of legs. Two dimensions were used to define the thickness of Greebles' tails and the length of Timbos' legs: thick-tail vs. thin- tail, long-legs vs. short-legs. In one of the two creature groups, each dimension has three different variants, resulting in 6 creatures in total for each creature group: Among Greebles (See Figure 6): thick-tailed1, thick- tailed2, thick-tailed3; thin- tailed1, thin-tailed2, thin-tailed3. Among Timbos (See Figure 7): long-legged1, long-legged2, long-legged3, shortlegged1, short-legged2, short-legged3. In addition, to make visual stimuli become comparable to the vowel quality variation in Experiment One, the 
shape of the ears of Greebles and Timbos varied on the continuum,
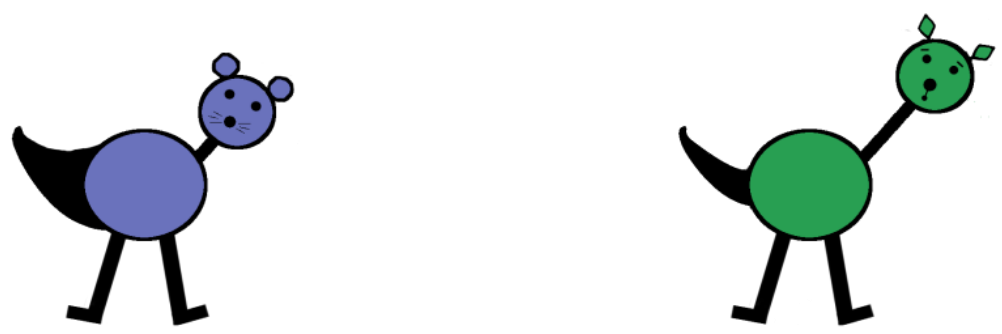

Figure 5: A Greeble (left) and Timbo (right).

respectively: The round-eared Greebles' ears varied inching toward diamondshaped and the diamond-eared Timbos' ears varied by inching toward roundshaped. Within each category, there were three different variants of the ears. The variation of the ear shapes of creatures in Experiment Two is analogous to the vowel quality variation in Experiment One.

\subsubsection{Apparatus and Procedure}

The apparatus and procedure of conducting Experiment Two were very similar to that of Experiment One, except that visual stimuli were presented instead of sound stimuli.

\subsubsection{Visual-Discrimination Task}

Before Experiment Two started, the one child with DLD and 16 children with TLD had not participated in any explicit visual learning experiment, and 13 children with TLD had completed an explicit visual learning experiment. 
The one child with DLD and 15 children with TLD learned visual stimuli taken from the legs categories, and 14 children with TLD learned visual stimuli taken from the tail categories.

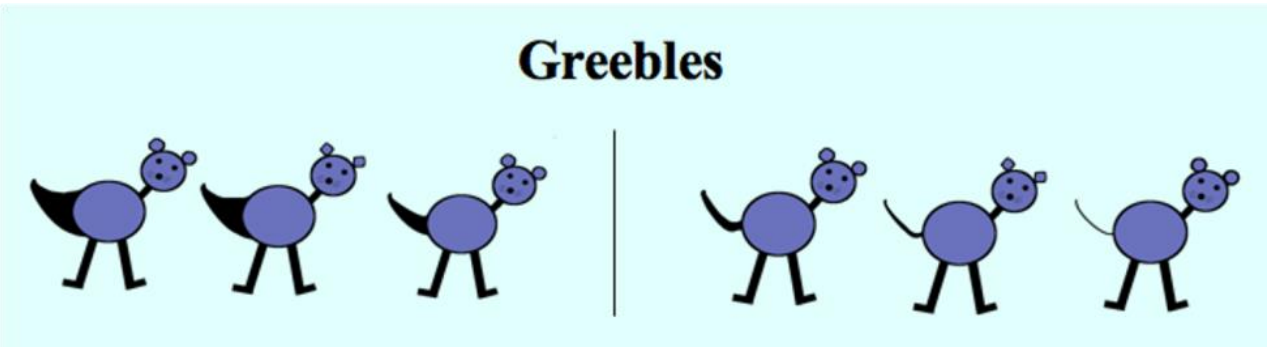

Figure 6: Greebles on a continuum: Adapted from Quam et al. (2019).

For the visual-discrimination task, children saw 12 pairs of visual images from a set of 6 visual stimuli (creatures differing in legs or tail) that are part of a continuum including the thickness of Greebles' tails or the length of Timbos' legs differing from each other visually in 1-5 steps, resulting in 12 trials in total. In each trial, children looked at two creatures. Children were told to look at both creatures and say "same" or "different", depending on whether they thought the two creatures were identical or not.

Following the procedure in the discrimination task in Experiment One, children's responses in the visual discrimination task were calculated as dprime scores.

\subsubsection{Implicit Visual-Mapping Task}

The implicit visual-mapping task was created to encourage children to look at visual stimuli and implicitly learn to link the visual stimuli to other objects. Similar to the implicit sound-meaning-mapping task in Experiment One, the 
implicit visual- mapping task in Experiment Two also had three parts: familiarization phase, the main section of the experiment (two training blocks and one test block), and one production task.

In the familiarization phase, a creature named Greeble or Timbo was

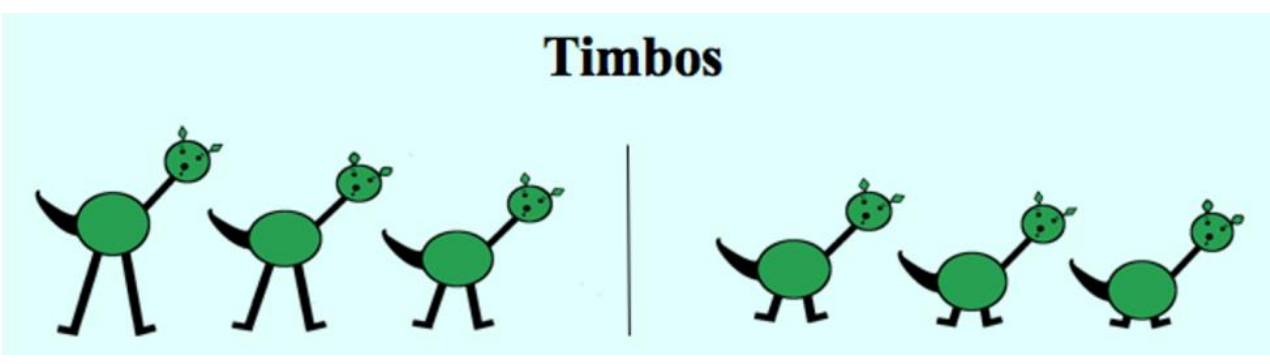

Figure 7: Timbos on a continuum: Adapted from Quam et al. (2019).

introduced to the children. Children were told that some Greebles/Timbos "are always thirsty," and some "are always hungry." Then they were asked to find out if the creatures "are the kind of Greeble/Timbo that always wants food or the kind of Greeble/Timbo that always wants to drink (See Figure 8)." Similar to Experiment One, Experiment Two also included a drink icon (different from that was used in Experiment One) attached with Velcro to the left arrow key on the keyboard, and a food icon (different from that was used in Experiment One) attached with Velcro to the right arrow key.

Similar to Experiment One, there were two training blocks and one test block in the main section of Experiment Two. Each block included 24 trails, resulting in 72 trials in total. In the training blocks, the correct object (food or drink) would appear on the screen a few milliseconds after an image of a Greeble/Timbo showed up on the screen. 
In the production task after the mapping task, children were asked, "Can you tell me what the Greebles/Timbos who always wanted to eat food/drink looked like?" The task was designed to let children verbally describe the visual features they might be using to differentiate the categories. We chose not to prompt children for drawing, as we believed that they might not have the capacity to draw $\mathrm{t}$

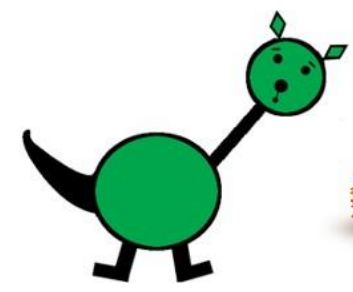

sscription of the

Figure 8: Either the drink (left) or the food (right) appears on the screen next to a Greeble/Timbo after a delay.

creatures was not exactly the same as imitation of the sounds in Experiment

One, we hoped it would still shed light on children's learning in a similar way.

\subsection{Results}

\subsubsection{Visual Discrimination}

\section{Children with TLD}

A MANOVA was conducted to investigate how d-prime scores were associated with the between-subjects predictors Cue (legs vs. tail) and First Task (legs-first vs. tail-first) and the within-subjects predictor Distance on the Continuum (steps 1-5). The MANOVA revealed a significant main effect of Distance $($ Wilks' $\Lambda=.204, F(4,22)=21.497, p<.001)$. To further examine the main effect of Distance, we conducted planned multiple comparison tests with Bonferroni correction to compare the d-prime scores for adjacent 
distance pairs, following a similar procedure of examining the main effect of distance in the sound discrimination task of Experiment One. The tests revealed that the d-prime scores were significantly higher for Distance 3 than for Distance $2(t(28)=-4.296, p<0.001)$, and no significant difference was found among the rest of the three adjacent distance pairs. As stated in Statistical Design in Chapter II, there is a violation of the normality assumption on visual discrimination data. Therefore, we plan in the future to run a non-parametric permutation test.

While a significant interaction of Distance on the Continuum (steps 1-5) by Cue (pitch vs. duration) was found in Experiment One, no significant interaction of Distance on the Continuum (steps 1-5) by Cue (legs vs. tail) was found.

Additional MANCOVAs were conducted to examine whether Age, Gender, or Primary Caregiver Education affected the participants' performance on visual dis- crimination tasks. We found that the main effect of Distance became non-significant in the models when the covariates Age $($ Wilks' $\Lambda=.795, F(4,21)=1.356, p=.283)$, Gender $($ Wilks' $\Lambda=.917, F(4$, $21)=.476, p .753)$, and Primary Caregiver Education $($ Wilks' $\Lambda=.891, F(4$, 20) $=.612, p=.659)$ were included.

One Child with DLD

Table 6 lists the visual d-prime scores for children with TLD and the one child with DLD who learned the legs categories. The d-prime scores of the one child with DLD for each distance fell within the range of the d-prime scores of children with TLD and were within 1 SD from the mean. 


\subsubsection{Implicit Visual Mapping}

Children with TLD

The accuracy of the visual-mapping of children with TLD was computed, and similar procedure following that in Experiment One was used to examine children's performance on the implicit visual-mapping task. To examine children's implicit visual-mapping accuracy of visual stimuli in two cues, a MANOVA was conducted including between-subject predictors Cue (legs vs. tail) and First Task (legs-first vs. tail-first) and the within-subject predictor Phase in the Test Block (phase one vs. phase two). The test revealed that there was a significant effect of Cue (legs vs. tail) on visual-meaning mapping accuracy scores $(F(1,25)=9.150, p=.006)$, indicating that children with TLD learned the legs categories $(\mathrm{M}=86.1 \%, \mathrm{SD}=0.17)$ significantly better than the tail categories $(M=63.4 \%, S D=0.22)$.

To compare the reaction time in two training blocks, a MANOVA was conducted, including the between-subjects predictors Cue (legs vs. tail) and First Task (legs-first vs. tail-first) and the dependent variable Reaction Time

in training blocks (one vs. two). The test revealed a significant three-way interaction of Block by Cue (legs vs. tail) by First Task (legs-first vs. tail-first) $($ Wilk' $\Lambda=.819, F(1,25)=5.531, p=.027)$.

To further examine the three-way interaction, we conducted four paired t-tests on training block one vs. training block 2 for 1) children who learned legs categories first; 2) children who learned legs categories second; 3) children who learned tail categories first; 4) children who learned tail categories second. The tests revealed that throughout the training blocks, children who learned the legs categories first reacted to the stimuli faster 
than those who learned the legs categories second, and the rest of the three groups reacted to the stimuli slower than their compared groups. In particular, children who learned the tail categories first reacted to the stimuli significantly slower in the training block two than they did in the training block one $(\mathrm{t}(6)=-3.774, \mathrm{p}=.009)$. It is important to note that the average age of children who learned the tail categories implicitly was one month and four days younger than the average age of those who learned the legs categories implicitly.

To compare the reaction time in the two phases of the test block, a MANOVA was conducted including the between-subjects predictors Cue (legs vs. tail) and First Task (legs-first vs. tail-first), the within-subjects predictor Phase (one vs. two of the test block), and the dependent variable Reaction Time. The MANOVA revealed no significant main effects or interactions.

\section{One Child with DLD}

The child with DLD learned the visual categories including creatures that differed in legs and completed the implicit visual-meaning task with $95.8 \%$ accuracy of learning. The child's reaction time to stimuli in the second training block $(2.93 \mathrm{sec})$ was not faster than in the first training block $(3.05 \mathrm{sec})$. The child's reaction time to stimuli was not faster in the second phase of the test block $(2.31 \mathrm{sec})$ than that in the first phase of the test block $(2.26 \mathrm{sec})$, either.

The accuracy score of the child with DLD (95.8\%) on the legs category learning task is within $1 \mathrm{SD}$ above the mean of the accuracy scores of children with TLD (See Table 7). The average reaction time of the child with DLD was 2.989 seconds in training blocks and 2.288 seconds in the 
test block. Compared to the legs category data for children with TLD, the reaction time of the child with DLD was within 1 SD below the mean of the accuracy scores of children with TLD in the training blocks, and within 1 SD below the mean of the accuracy scores of children with TLD in the test block (See Table 8). 


\begin{tabular}{|c|c|c|c|c|c|c|}
\hline \multicolumn{2}{|c|}{ Distance } & 1 & 2 & 3 & 4 & 5 \\
\hline \multirow{3}{*}{$\begin{array}{l}\text { D- } \\
\text { prime } \\
\text { Scores } \\
\text { Overall } \\
\text { (TLD) }\end{array}$} & mean & 1.385 & 1.492 & 4.049 & 4.475 & 4.688 \\
\hline & SD & 2.420 & 2.280 & 2.873 & 2.275 & 2.280 \\
\hline & Range & $\begin{array}{l}(-3.09- \\
6.18)\end{array}$ & $\begin{array}{l}(- \\
3.09- \\
6.18)\end{array}$ & $\begin{array}{l}(- \\
3.09- \\
6.18)\end{array}$ & $\begin{array}{l}(.00- \\
6.18)\end{array}$ & $\begin{array}{l}(- \\
3.09- \\
6.18)\end{array}$ \\
\hline \multirow{3}{*}{$\begin{array}{l}\text { D- } \\
\text { prime } \\
\text { scores } \\
\text { for } \\
\text { Legs } \\
\text { (TLD) }\end{array}$} & mean & .618 & 1.236 & 4.532 & 4.532 & 4.944 \\
\hline & SD & 2.089 & 1.954 & 2.297 & 2.297 & 1.954 \\
\hline & Range & $\begin{array}{l}(- \\
3.09- \\
6.18)\end{array}$ & $\begin{array}{l}(- \\
3.09- \\
6.18)\end{array}$ & $\begin{array}{l}(.00- \\
6.18)\end{array}$ & $\begin{array}{l}(.00- \\
6.18)\end{array}$ & $\begin{array}{l}(.00- \\
6.18)\end{array}$ \\
\hline $\begin{array}{l}\text { D- } \\
\text { prime } \\
\text { scores } \\
\text { for } \\
\text { Legs } \\
\text { (DLD) }\end{array}$ & mean & 0 & 3.09 & 3.09 & 6.18 & 6.18 \\
\hline \multirow{3}{*}{$\begin{array}{l}\text { D- } \\
\text { prime } \\
\text { scores } \\
\text { for Tail } \\
\text { (TLD) }\end{array}$} & mean & 2.207 & 1.766 & 3.531 & 4.413 & 4.413 \\
\hline & SD & 2.551 & 2.632 & 3.397 & 2.336 & 2.632 \\
\hline & Range & $\begin{array}{l}(- \\
3.09- \\
6.18)\end{array}$ & $\begin{array}{l}(- \\
3.09- \\
6.18)\end{array}$ & $\begin{array}{l}(- \\
3.09- \\
6.18)\end{array}$ & $\begin{array}{l}(.00- \\
6.18)\end{array}$ & $\begin{array}{l}(- \\
3.09- \\
6.18)\end{array}$ \\
\hline
\end{tabular}

Table 6: Visual d-prime scores across five distances for children with TLD (mean, standard deviation, and range) and one child with DLD (mean).

\begin{tabular}{|l|l|l|l|}
\hline Cue & Mean & $\begin{array}{l}\text { Standard } \\
\text { deviation }\end{array}$ & Range \\
\hline Legs & $\begin{array}{l}86.1 \% \\
\text { (One child } \\
\text { with }\end{array}$ & .167 & $\begin{array}{l}(54.2 \%- \\
100.0 \%)\end{array}$ \\
\hline DLD: 95.8\%) & $63.39 \%$ & .212 & $\begin{array}{l}(37.5 \%- \\
91.67 \%)\end{array}$ \\
\hline
\end{tabular}

Table 7: Accuracy of the visual mapping of children with TLD and one child with DLD 


\begin{tabular}{|l|l|l|l|l|}
\hline Cue & Block & Mean & $\begin{array}{l}\text { Standard } \\
\text { deviation }\end{array}$ & Range \\
\hline Legs & Training & $\begin{array}{l}3.360(\text { One } \\
\text { child with } \\
\text { DLD: } \\
2.989)\end{array}$ & .867 & $\begin{array}{l}(2.566- \\
6.083)\end{array}$ \\
\cline { 2 - 5 } & Test & $\begin{array}{l}3.290(\text { One } \\
\text { child with } \\
\text { DLD: } \\
2.288)\end{array}$ & 1.484 & $\begin{array}{l}(1.677- \\
6.984)\end{array}$ \\
\hline \multirow{2}{*}{ Tail } & Training & 3.377 & .555 & $\begin{array}{l}(2.024- \\
4.249)\end{array}$ \\
\cline { 2 - 5 } & Test & 3.522 & 1.559 & $\begin{array}{l}(1.113- \\
6.276)\end{array}$ \\
\hline
\end{tabular}

Table 8: Reaction time (seconds) of the visual-mapping of children with TLD and one child with DLD

\subsubsection{Linking Visual Discrimination and Implicit Visual Mapping}

\section{Children with TLD}

Multivariate analyses of covariance (MANCOVAs) were conducted to examine the association between visual discrimination scores and the accuracy of visual learning among children with TLD. The MANCOVAs included Cue (legs vs. tail), First Task (legs-first vs. tail-first), Phase in the Test Block (phase one vs. phase two) as categorical predictors, and D-Prime Score as a continuous predictor. As in Experiment One, we ran two models, one with the average D-prime scores across five distance, and one with D-prime in Distance 5 as the covariate. The first model revealed a significant main 
effect of Phase $($ Wilks' $\Lambda=.814, F(1,24)=5.467, p=.028)$, with the mapping accuracy in phase one $($ Mean $=75.6 \%, S D=.239)$ higher than that in phase two $($ Mean $=74.7 \%, S D=.234)$, and a significant effect of Cue (legs vs. tail) $(F(1,24)=8.942, p=.006)$, with the mapping accuracy of the legs categories $($ Mean $=86.1 \%, S D=.167)$ higher than that of the tail categories $($ Mean $=63.4 \%, S D=.212)$. A significant interaction of Phase with the average d-prime scores across five distances was also found $($ Wilks' $\Lambda=.788, F(1,24)=6.472, p=.018)$.

In order to further investigate the interaction stated above, simple Pearson's correlation tests similar to the supplemental examination in Experiment One were run in Experiment Two. In phase one of the test block, there was a negative correlation between visual mapping accuracy and the average d-prime scores across five distances $(r=-.345, p=.067)$. In phase two of the test block, the correlation be- tween visual mapping accuracy and the average d-prime scores across five distances was negligibly positive ( $r=$ $.009, p=.961)$. The correlation between visual mapping accuracy and the average d-prime scores across five distances was negative for both the legs categories $(r=-.359, p=.188)$ and the tail categories $(r=-.115, p=.696)$. Throughout the test block (including both phases one and two), there was a negative correlation between mapping accuracy and the average d-prime scores across five distances $(r=-.182, p=.344)$.

One Child with DLD 


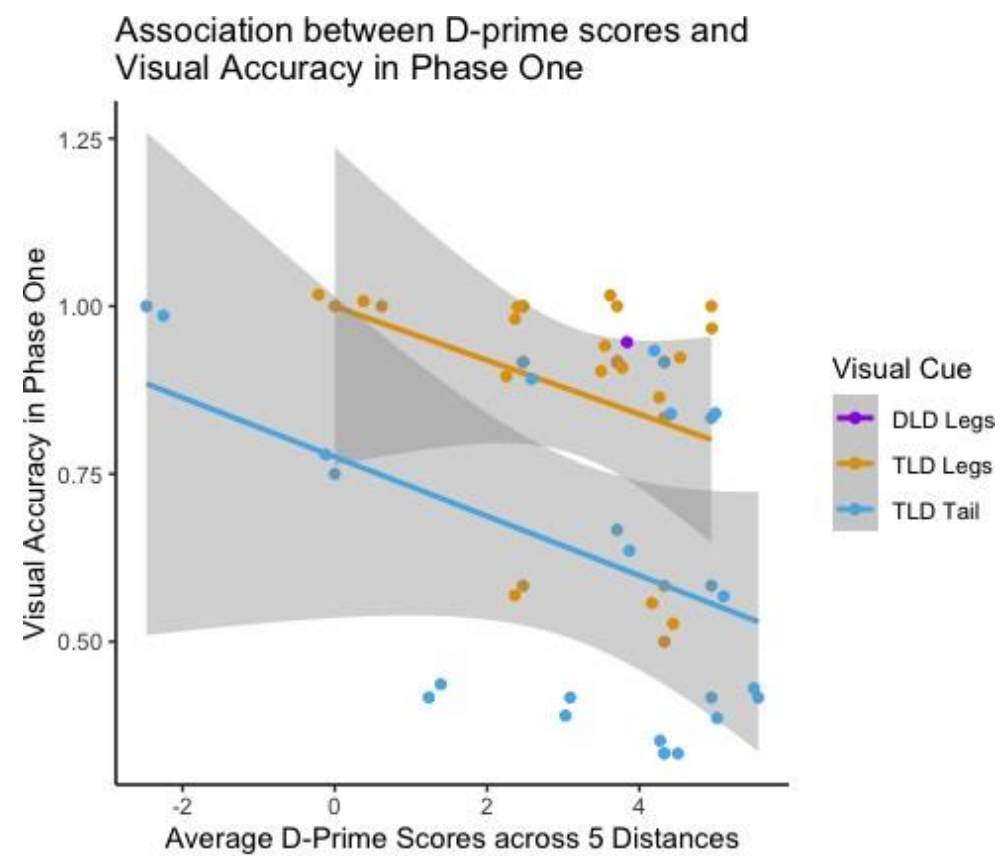

Figure 9: Association (with 95\% confidence intervals) be- tween visual discrimination and mapping in phase one of the test block

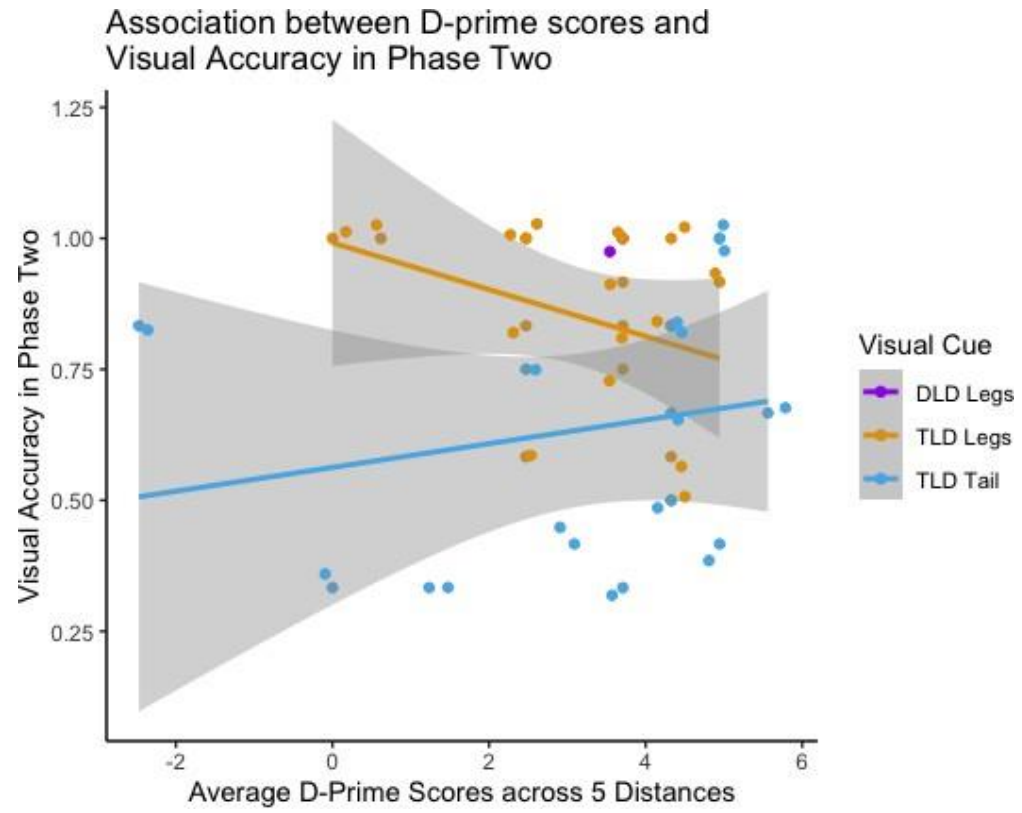

Figure 10: Association (with 95\% confidence intervals) between visual discrimination and mapping in phase two of the test block 
Figures 9 and 10 depict the relationship between the average d-prime scores across five distances and visual accuracy scores in two phases of the test block for children with TLD, as well as two data points that represent the performance of the child with DLD. The child with DLD learned the legs categories, and in both phases, the child's performance was not falling on the regression line that approximates the performance of the children with TLD who learned the legs categories. In addition, the performance of the child with DLD was within the 95\% confidence intervals of the legs category data for children with TLD in phase one and outside the $95 \%$ confidence intervals of the performance of the TLD group in phase two. Similar to the explanation of the performance of the child with DLD stated in Experiment One, the child with DLD also achieved high mapping accuracy scores in Experiment Two, compared to their average visual discrimination score (3.708), which is not as high as the ceiling d-prime score (6.18).

\subsection{Discussion}

Experiment Two provided evidence that the visual discrimination sensitivity of children with TLD varied depending on how far apart the two visual stimuli they saw were, and children's visual discrimination sensitivity tended to be higher when the two visual stimuli were further apart from each other, which was only found between distance 3 and distance 2 . In addition, it was found that children with TLD learned visual stimuli including creatures differing in legs better than those including creatures differing in the tail. No significant difference was found in children's reaction time either in two 
training blocks or in the two phases of the test block. Furthermore, Experiment Two suggested that there was an association between visual discrimination scores and later visual learning, which is significantly different in phase one vs. phase two. Finally, there was a negligibly positive correlation between visual discrimination and visual learning of the second phase in the test block, suggesting that links were starting to emerge as children learned the categories.

The visual discrimination sensitivity (legs categories) of the one child with DLD was comparable to that of children with TLD who learned the same categories and the performance of the child with DLD on the implicit legs category learning task was better than that of the children with TLD, with $100 \%$ accuracy of learning. 


\section{CHAPTER IV: General Discussion}

\subsection{Compare and Contrast: Experiment One and the Previous Explicit Study}

Both Experiment One and the previous explicit study found that the auditory discrimination sensitivity of children varied depending on the distance between the two sounds they heard. While Experiment One did not find that the children's discrimination sensitivity in the TLD group significantly differed across distances, the previous explicit study found that children's discrimination sensitivity was higher for distance 3 than for distance 2. However, it is worth noting that when analyzing discrimination data with the use of inferential statistics, the previous explicit study included both children with and without DLD and Experiment One only included children with TLD.

Experiment One found that the pitch discrimination sensitivity of one child with DLD was comparable to their peers with TLD. In contrast, the previous explicit study reported higher auditory discrimination sensitivity overall among children with TLD than their peers with DLD.

In addition, Experiment One confirmed the pitch learning of children with TLD that was found in Quam et al. (2020). However, despite the modification of the sound stimuli in Experiment One, children with TLD still did not present robust learning of the duration categories, which was similar to the findings in the previous explicit study.

Apart from the models used in the previous study to examine children's performance on sound-meaning-mapping accuracy tasks, Experiment One also included models that analyzed reaction time revealing that in both the training blocks and the test block, children with TLD who learned pitch 
categories reacted to the sound stimuli faster than those who learned duration categories, which confirmed the ad-vantage of pitch category learning among children with TLD. It suggested that in the training blocks, children might be just responding faster when they saw an object as if the sound primed them to expect the object and that in the test block, children were using the pitch stimuli to guess which object would appear.

While the previous explicit study found that discrimination sensitivity was marginally associated with sound-meaning-mapping accuracy, an association between sound dis- crimination scores and sound-meaning-mapping accuracy was not observed in Experiment One.

\subsection{Compare and Contrast: Experiment One and Experiment Two}

Both experiments in the current study found that the discrimination sensitivity of children with TLD varied depending on how far apart the two stimuli they heard or saw were. Experiment One did not demonstrate significant differences of children's discrimination sensitivity among any of the distances. In contrast, Experiment Two revealed that children's visual discrimination sensitivity was significantly higher for Distance 3 than for Distance 2, which demonstrated a similar pattern found in the previous explicit study where sound discrimination sensitivity was found to be mostly asymptoted by Distance 3 (Quam et al., 2020). Furthermore, both experiments pro- vided evidence that children with TLD learned one type of categories better than the other type of categories within the same domain (auditory or visual: pitch category learning better than duration category learning; legs category learning better than tail category learning). 
Although there was a lack of evidence that sound discrimination scores were associated with later sound stimuli learning in Experiment One, an interaction between visual discrimination scores and later visual stimuli learning was found in Experiment Two. Further examination of the interaction in Experiment Two revealed a negligibly positive correlation between visual discrimination and visual learning of the second phase in the test block, indicating that links were starting to show up as children learned the categories.

In addition, in both experiments, the discrimination sensitivity of the child with DLD was comparable to their peers with TLD. In both experiments, the performance of the child with DLD on the learning tasks was also above the average performance of their peers with TLD. These findings contrast with the previous finding that the sound discrimination sensitivity of children with TLD was higher than that of children with DLD, although Experiment Two used visual instead of auditory stimuli. Given that only one child with DLD was included in the current study, we will have to wait to see whether the comparison of children with and without DLD in the current study holds up as we include more children with DLD.

\subsection{Overall Findings and the Primary Hypotheses}

The purpose of the current study was to test two hypotheses: the Procedural Deficit Hypothesis (Ullman and Pierpont, 2005) and the auditory-processingdeficit hypothesis (Merzenich et al., 1996; Tallal et al., 1996; Wright et al., 1997). Based on the Procedural Deficit Hypothesis (Ullman and Pierpont, 2005), we predicted that children with TLD would show learning in both experiments and that children with DLD would have difficulty learning stimuli 
in both experiments. Based on the auditory-processing-deficit hypothesis (Merzenich et al., 1996; Tallal et al., 1996; Wright et al., 1997), we predicted that there might be an additive impact of impairments in DLD in the auditory condition.

The current study found that children with TLD learned one of the auditory categories (pitch) and both of the visual categories (legs and tail) implicitly, which confirmed part of our prediction about the implicit learning of children with TLD. However, the implicit duration learning of children with TLD was below chance level, which did not support our prediction that children with TLD would demonstrate implicit learning of the duration categories. In addition, the child with DLD showed implicit learning in both experiments where they learned the pitch categories and the legs categories, and their performance regarding accuracy scores in the mapping tasks was above the average performance of their peers with TLD. This did not support our prediction that children with DLD would show difficulty learning stimuli implicitly. However, we cannot strongly test the hypotheses until we have recruited enough children with DLD.

The current study also observed that the sensitivity to both sound and visual stimuli among children with TLD depends on the distance of the stimuli on the continuum. In addition, children with TLD were more sensitive to pitch categories than duration categories, and they were more sensitive to the legs categories than the tail categories. The discrimination sensitivity of one child with DLD was comparable to that of those who learned the same categories (pitch categories for sound stimuli and legs categories for visual stimuli).

The current study did not find an association between sound discrimination and meaning-mapping for children with TLD in sound learning tasks but an 
interaction between visual discrimination and visual mapping among children with TLD was found, with a negligibly positive correlation between visual discrimination and visual mapping of the second phase in the test block, indicating that links were starting to emerge as children learned the categories. The performance of one child with DLD was neither falling on the regression line on sound learning tasks (pitch categories) for the TLD group nor on the regression line on visual learning tasks (legs categories) for the TLD group, which could be explained that the child received relatively high accuracy scores for both sound and visual learning tasks and demonstrated average discrimination sensitivity.

\subsection{Limitations and Future Directions}

One of the major limitations of the current study was the small sample size of children with DLD. We only recruited one child with DLD in the current study, which was due to recruitment complications and delays. In the future, we hope to recruit enough children with DLD to continue testing our hypotheses.

Another limitation of the current study, specifically related to Experiment One, was that the sound stimuli were synthesized and isolated vowels that do not resemble real word learning. Prior studies have found that the performance of children with DLD on categorical perception tasks involving meaningful syllables was comparable to the performance of their peers with TLD when the stimuli were naturally generated (Coady et al., 2007; Coady et al., 2005).

A third limitation of the current study, as stated above, was that robust learning of the duration categories was not observed among children with TLD, which was also observed in Quam et al. (2020). Therefore, tasks 
including the duration condition would be a less strong test of the hypotheses since there will not be a robust baseline for performance in the TLD group. In addition, children's less robust learning of the duration categories may be due to the trajectory of the development of duration discrimination sensitivity, as evidence has shown that 4- and 5-year-olds, in general, did not have adultlike auditory duration discrimination skills (Jensen and Neff, 1993) and these skills are considered to be acquired between age eight and age ten (Elfenbein et al., 1993). Furthermore, the duration dimension is usually judged within contexts (Quam et al., 2020). Therefore, providing contexts such as whole words may help children better discriminate and learn duration categories. In conclusion, for the future plans of the current study, we may only run the following tasks without testing the duration condition: 1) implicit pitch categories learning; 2) implicit legs categories learning; 3) implicit tail categories learning.

In summary, regarding future plans for the current study, we hope to recruit more children with DLD and run experiments without the duration condition. As for future studies, we plan to use sound stimuli embedded in naturally recorded whole words to provide more context for word learning and hope that would boost children's learning of sounds. 


\section{BIBLIOGRAPHY}

Alt, M., Plante, E., and Creusere, M. (2004). Semantic Features in FastMapping Performance of Preschoolers With Specific Language Impairment Versus Preschoolers With Normal Language. $J$ Speech Lang Hear Res Journal of Speech, Language, and Hearing Research, 47(2):407-420.

Ashby, F. G. and Maddox, W. T. (2005). Human category learning. Annual review of psychology, 56:149-78.

Bishop, D. V. M. and Mcarthur, G. M. (2004). Immature cortical responses to auditory stimuli in specific language impairment: Evidence from ERPs to rapid tone sequences. Developmental Science, 7(4):F11F18.

Bishop, D. V. M., Snowling, M. J., Thompson, P. A., and Greenhalgh, T. (2017). Phase 2 of CATALISE: A multinational and multidisciplinary Delphi consensus study of problems with language development: Terminology. Journal of Child Psychology and Psychiatry, 58(10):1068-1080.

Boersma, P. and Weenink, D. (2008). Praat: Doing phonetics by computer (Version 5.0.30) [Computer program].

Cleeremans, A. (2006). Implicit Learning Models. In Encyclopedia of Cognitive Science. American Cancer Society.

Coady, J., Evans, J., Mainela-Arnold, E., and Kluender, K. (2007). Children With Specific Language Impairments Perceive Speech Most Categorically When Tokens Are Natural and Meaningful. Journal of Speech, Language, and Hearing Research, 50(1):41-57.

Coady, J., Kluender, K., and Evans, J. (2005). Categorical Perception of Speech by Children with Specific Language Impairments. Journal of Speech, Language, and Hearing Research, 48(4):944-959.

Corriveau, K., Pasquini, E., and Goswami, U. (2007). Basic Auditory Processing Skills and Specific Language Impairment: A New Look at an Old Hypothesis. Journal of Speech, Language, and Hearing Research, 50(3):647-666.

Cumming, R., Wilson, A., and Goswami, U. (2015). Basic auditory processing and sensitivity to prosodic structure in children with specific language impairments: A new look at a perceptual hypothesis. Frontiers in Psychology, 6. 
Datta, H., Shafer, V. L., Morr, M. L., Kurtzberg, D., and Schwartz, R. G. (2010). Electrophysiological Indices of Discrimination of LongDuration, Phonetically Similar Vowels in Children With Typical and Atypical Language Development. Journal of Speech, Language, and Hearing Research, 53(3):757-777.

Dawson, J. I., Stout, C., Eyer, J., Tattersall, P. J., Fonkalsrud, J., Croley, K., and Janelle Publications (Firm) (2005). SPELT-P 2: Structured Photographic Expressive Language Test. Janelle Publications, DeKalb, Ill.

Dunn, L. M., Dunn, D. M., and Pearson Assessments (2007). PPVT-4: Peabody Picture Vocabulary Test. Pearson Assessments, Minneapolis, MN.

Elfenbein, J., Small, A., and Davis, J. (1993). Developmental patterns of duration discrimination. Journal of speech and hearing research, 36(4):842-9.

Gabriel, A., Maillart, C., Guillaume, M., Stefaniak, N., and Meulemans, T. (2011). Exploration of Serial Structure Procedural Learning in Children with Language Impairment. Journal of the International Neuropsychological Society, 17(2):336-343.

Gabriel, A., Meulemans, T., Parisse, C., and Maillart, C. (2015). Procedural learning across modalities in French-speaking children with specific language impairment. 36(3):747-769.

Gabriel, A., Stefaniak, N., Maillart, C., Schmitz, X., and Meulemans, T. (2012). Procedural visual learning in children with specific language impairment. research article.(Research Article)(Report). American Journal of Speech-Language Pathology, 21(4):329-341.

Goldman, R., Fristoe, M., and American Guidance Service (Firm) (2000). Gold- man Fristoe 2 Test of Articulation. American Guidance Service, Circle Pines, MN (Publishers' Bldg., Circle Pines 550141796).

Gray, S. (2005). Word Learning by Preschoolers With Specific Language

Impairment. Journal of Speech, Language, and Hearing Research, 48(6):1452-1467.

Gray, S. (2006). The relationship between phonological memory, receptive vocabulary, and fast mapping in young children with specific language impairment. Journal of speech, language, and hearing research: JSLHR, 49(5):955-969.

Greenslade, K. J., Plante, E., and Vance, R. (2009). The diagnostic accuracy 
and con- struct validity of the structured photographic expressive language test-preschool: Second edition. Language, speech, and hearing services in schools, 40(2):150-160.

Hedenius, M., Persson, J., Tremblay, A., Adi-Japha, E., Ver'1ssimo, J., Dye, C. D., Alm, P., Jennische, M., Bruce Tomblin, J., and Ullman, M. T. (2011). Grammar predicts procedural learning and consolidation deficits in children with Specific Language Impairment. Research in Developmental Disabilities, 32(6):2362-2375.

Henry, L. A., Messer, D. J., and Nash, G. (2012). Executive functioning in children with specific language impairment. Journal of Child Psychology and Psychiatry, 53(1):37-45.

Jackson, E., Leitao, S., and Claessen, M. (2016). The relationship between phonological short-term memory, receptive vocabulary, and fast mapping in children with specific language impairment STM, receptive vocabulary and fast mapping in children with SLI. International Journal of Language \& Communication Disorders International Journal of Language \& Communication Disorders, 51(1):61-73.

Jensen, J. K. and Neff, D. L. (1993). Development of Basic Auditory Discrimination in Preschool Children. Psychological Science, 4(2):104-107.

Kapantzoglou, M., Restrepo, M. A., Gray, ., and Thompson, M. S. (2015). Language Ability Groups in Bilingual Children: A Latent Profile Analysis. Journal of Speech, Language, and Hearing Research, 58(5):1549-1562.

Kaufman, A. S. and Kaufman, N. L. (2004). Kaufman Assessment Battery for Children. American Guidance Service, Circle Pines.

Kemény, F. and Lukács, Á. (2010). Impaired procedural learning in language impairment: Results from probabilistic categorization. Journal of Clinical and Experimental Neuropsychology Journal of Clinical and Experimental Neuropsychology, 32(3):249-258.

Klatt, D. H. and Klatt, L. C. (1990). Analysis, synthesis, and perception of voice quality variations among female and male talkers. The Journal of the Acoustical Society of America, 87(2):820-857.

Kujala, T. and Leminen, M. (2017). Low-level neural auditory discrimination dysfunctions in specific language impairment-A review on mismatch negativity findings. Developmental Cognitive Neuroscience, 28:65-75. 
Kwok, E. Y. L., Joanisse, M. F., Archibald, L. M. D., and Cardy, J. O. (2018). Immature Auditory Evoked Potentials in Children With Moderate-severe Developmental Language Disorder.(Research Article). Journal of Speech, Language, and Hearing Research, 61(7):1718-1730.

Legendre, P. and Legendre, L. (1998). Numerical Ecology.

Leonard, L. B. (2014a). Children with Specific Language Impairment. The MIT Press, Cambridge, Massachusetts ; London, England, second edition. edition.

Leonard, L. B. (2014b). Specific Language Impairment Across Languages. Child development perspectives, 8(1):1-5.

Leonard, L. B. and Kueser, J. B. (2019). Five overarching factors central to grammatical learning and treatment in children with developmental language disorder. International Journal of Language \& Communication Disorders, 54(3):347-361.

Lum, J. A. G., Conti-Ramsden, G., Page, D., and Ullman, M. T. (2012). Working, declarative and procedural memory in specific language impairment. Cortex, 48(9):1138-1154.

Mcarthur, G. M. and Bishop, D. V. (2001). Auditory perceptual processing in people with reading and oral language impairments: Current issues and recommendations. Dyslexia (Chichester, England), 7(3):150-70.

Merzenich, M. M., Jenkins, W. M., Johnston, P., Schreiner, C., Miller, S. L., and Tallal, P. (1996). Temporal Processing Deficits of LanguageLearning Impaired Children Ameliorated by Training. Science, 271(5245):77-81.

Oram Cardy, J. E., Flagg, E. J., Roberts, W., and Roberts, T. P. L. (2008). Auditory evoked fields predict language ability and impairment in children. International journal of psychophysiology : official journal of the International Organization of Psychophysiology, 68(2):170-175.

Peirce, J. W. (2007). PsychoPy-Psychophysics software in Python. Journal of neuroscience methods., 162(1):8.

Poll, G. H., Miller, C. A., and van Hell, J. G. (2015). Evidence of compensatory processing in adults with developmental language impairment: Testing the predictions of the procedural deficit hypothesis. Journal of Communication Disorders, 53:84-102. 
Quam, C., Cardinal, H., and Gallegos, C. (2017a). Implicit and explicit learning of sound categories by preschoolers with and without specific language impairment. In Symposium on Research in Child Language Disorders, Madison, WI.

Quam, C., Cardinal, H., and Gallegos, C. (in prep.). Implicit SoundMeaning Mapping in Preschoolers with and Without Developmental Language Disorder.

Quam, C., Cardinal, H., Gallegos, C., and Bodner, T. (2020). Sound discrimination and explicit mapping of sounds to meanings in preschoolers with and without developmental language disorder. International Journal of Speech-Language Pathology, 0(0):1-12.

Quam, C., Knight, S., and Gerken, L. (2017b). The Distribution of Talker Variability Impacts Infants' Word Learning. Laboratory Phonology: Journal of the Association for Laboratory Phonology, 8(1):1.

Quam, C., Yu, W., and Franz, M. (2019). Sound Discrimination and SoundMeaning Mapping in Preschoolers with and Without Developmental Language Disorder (And What We've Learned Along the Way About the Research Process).

Richards, S. and Goswami, U. (2015). Auditory processing in specific language impairment (SLI): Relations with the perception of lexical and phrasal stress. Journal of Speech, Language, and Hearing Research, 58(4):1292-305.

Saletta, M., Goffman, L., Ward, C., and Oleson, J. (2018). Influence of Language Load on Speech Motor Skill in Children With Specific Language Impairment. (Research Article)(Report). Journal of Speech, Language, and Hearing Research, 61(3):675- 689.

Schwartz, R. G., Scheffler, F. L. V., and Lopez, K. (2013). Speech perception and lexical effects in specific language impairment. Clinical Linguistics \& Phonetics, 27(5):339-354.

Shanks, D. R. (1996). Implicit learning. In In K. Lamberts \& R. Goldstone (Eds.), Handbook of Cognition, pages 202-220. Academic.

Sheng, L. and McGregor, K. (2010). Lexical-semantic organization in children with specific language impairment. J. Speech Lang. Hear. Res. Journal of Speech, Language, and Hearing Research, 53(1):146-159.

Stokes, S. F., Wong, A. M.-Y., Fletcher, P., and Leonard, L. B. (2006). Nonword Repetition and Sentence Repetition as Clinical Markers of Specific Language Impairment: The Case of Cantonese. Journal of Speech, 
Language, and Hearing Research, 49(2):219-236.

Tallal, P., Miller, S. L., Bedi, G., Byma, G., Wang, X., Nagarajan, S. S., Schreiner, C., Jenkins, W. M., and Merzenich, M. M. (1996). Language Comprehension in Language-Learning Impaired Children Improved with Acoustically Modified Speech. Science, 271(5245):81-84.

Ullman, M. (2001). The Declarative/Procedural Model of Lexicon and

Grammar. Journal of Psycholinguistic Research, 30(1):37-69.

Ullman, M. T. (2004). Contributions of memory circuits to language: The declarative/procedural model. Cognition, 92(1):231-270.

Ullman, M. T. (2016). Chapter 76 - The Declarative/Procedural Model: A Neurobiological Model of Language Learning, Knowledge, and Use.

Ullman, M. T., Earle, F. S., Walenski, M., and Janacsek, K. (2020). The Neurocognition of Developmental Disorders of Language. Annual Review of Psychology, 71(1):389-417.

Ullman, M. T. and Pierpont, E. I. (2005). Specific Language Impairment is not Specific to Language: The Procedural Deficit Hypothesis. Cortex, 41(3):399-433.

van der Lely, H. K. J. (2003). Do heterogeneous deficits require heterogeneous theories? SLI subgroups and the RDDR hypothesis. Language competence across populations: Toward a definition of specific language impairment, pages 109-133.

Weenink, D. (2009). The KlattGrid speech synthesizer. page 4.

Wright, B. A., Lombradino, L. J., King, W. M., Puranik, C. S., and al, e. (1997). Deficits in auditory temporal and spectral resolution in language-impaired children. Nature; London, 387(6629):176-8.

Younger, B. A. (1985). The Segregation of Items into Categories by TenMonth-Old Infants. Child Development, 56(6):1574-158 